\title{
Near-surface rock stress orientations in alpine topography derived from exfoliation fracture surface markings and 3D numerical modelling
}

\author{
Martin Ziegler $^{a^{*}}$, Simon Loew ${ }^{\mathrm{a}}$, Florian Amann ${ }^{\mathrm{a}}$ \\ ${ }^{a}$ Department of Earth Sciences, ETH Zurich, Switzerland \\ * Corresponding author. Tel.: +41 446322342; Fax: +41 446331108; E-mail: \\ martin.ziegler@erdw.ethz.ch; Geological Institute, Sonneggstrasse 5, NO G1.2.
}

\begin{abstract}
The fractographic analysis of plumose axis of exfoliation fracture surfaces from a preceding study in the Grimsel region of the Swiss Alps suggested complex directional trends of near-surface (i.e., within $\sim 100$ m below ground surface) maximum principal stress $\left(\sigma_{1}\right)$ trajectories within the investigated inner-trough valleys (i.e., U-shaped valleys). The stress trajectories describe a pattern governed by local topographic variations. In situ stress measurements from the region are scarce, locally scattered, based on different methods, and, thus, difficult to interpret at regional scale. In this study, we inferred that plumose structure axes form parallel to compressive $\sigma_{l}$, and improve our knowledge of the near-surface three-dimensional stress field in alpine settings with complex topography. We investigated near-surface stress tensors utilising three-dimensional, elastic numerical models. Our models account for morphological details of the Grimsel area at the decametre scale. We used two models with vertical bounda-

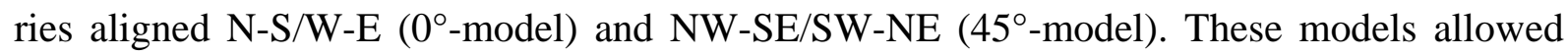
investigating gravitational stresses and superimposed isotropic and anisotropic compressive stresses arising from (active) tectonic shortening and/or stresses induced by exhumation (remnant stresses). Our model results illustrate that the superposition of gravitational stresses and realistic horizontal strains reveals complex near-surface stress trajectories that widely
\end{abstract}


follow the patterns of exfoliation fracture plumose axes. Our models demonstrate large variations of stress orientations within the shallow subsurface, including depth levels where exfoliation fractures formed. These variations cannot be captured by a small number of local stress measurements. Our study reveals that directional data from exfoliation fracture plumose axes of Middle to Upper Pleistocene ages can be used to constrain geologically recent and current maximum principal stress directions of the shallow subsurface of up to a few hundred meters below ground.

Keywords: finite-difference modelling; topographic stress perturbation; in situ stress measurements; alpine geomorphology; plumose structure axis; principal stress directions

\section{Introduction}

In situ rock mass stress orientations and magnitudes are key parameters relevant for the site characterisation phase of a wide range of geotechnical projects, such as underground excavations (e.g., for underground hydro-power plants), surface mining operations, petrothermal reservoir engineering, and for analysing slope and borehole stability. During the last three to four decades the techniques to estimate rock mass stress have substantially been improved and 'stress measurements' have become a standard practice [1,2]. Virgin stresses, i.e., stresses acting in a rock mass prior to man-made disturbances, of high-magnitude can cause brittle fracturing, e.g., around underground openings in massive rock (often referred to as spalling fractures [3]) and close to the landscape surface (e.g., exfoliation fractures [4-8]), and squeezing ground conditions in weak rock and/or heavily fractured rock masses with visco-plastic behaviour [9]. Within the uppermost parts of the crust rock mass stress magnitudes are mostly anisotropic, i.e., they are not lithostatic and at least two principal stress components are of 
unequal magnitude [10]. The maximum, intermediate, and minimum principal stresses are denoted $\sigma_{1}, \sigma_{2}$, and $\sigma_{3}\left(\sigma_{1}>\sigma_{2}>\sigma_{3}\right.$; compressive stresses are positive).

Besides stress magnitudes, principal stress orientations can be relevant for a project's design, e.g., in order to align large underground caverns either normal (at shallow depth) or parallel (at large depth) to the maximum principal stress orientation $[11,12]$. However, rock stress data are often rare, and in many cases, come from a rather small number of boreholes and borehole-based in situ stress measurements. In early project phases stress measurements might be absent. Furthermore, stress measurements in boreholes characterise the stress state within a limited volume, depending on the stress measurement method used (see, e.g., Tab. 7.2 in Zang and Stephansson [2]) and stress heterogeneities along the borehole. Lateral stress variations away from a borehole usually remain unknown.

Further difficulties in characterising rock mass stresses in the shallow subsurface may arise from complex, high-relief topography, such as in the Grimsel area of Switzerland. To date, most analytical and numerical studies on topographically-induced alteration of tectonic, and exhumation-induced remnant stresses are focused on two-dimensional cross valley geometries and show in-plane stress rotation (i.e., parallel to a valley cross profile), occurrence of tensile and compressive stresses, and changes of principal stress magnitudes along valley profiles. These studies contributed substantially to our understanding of stresses in (alpine) valley slopes [7,8,13-16]. However, only few published articles compared analytical or numerical model results with local in situ or palaeostress data, or discussed the three-dimensional orientations of principal stresses [17-20].

Exfoliation joints, also referred to as sheet or sheeting joints, are known to follow the present or former landscape surfaces [4]. Ziegler et al. [6,21] mapped the occurrence and properties of exfoliation joints in the granitic and granodioritic rock mass of the Grimsel region of the central Swiss Alps (also known as upper Hasli valley), and investigated their fracture- 
mechanical formation processes by analysing fracture surface morphologies (i.e., fractographic markings), such as plumose structures (also referred to as fracture plumes). Exfoliation joints in the Grimsel area are typically composed of several co-planar fracture plumes and formed at shallow depth, as deep as about $200 \mathrm{~m}$ below the ground surface. These exfoliation joints provide a superb opportunity to constrain shallow Pleistocene rock mass stresses. Most plumose structures visible on exfoliation joint surfaces are non-circular and contain a plumose axis that marks the locations of fastest fracture propagation and greatest mode I stress intensity, $K_{I}$, during fracture growth [21,22] (Fig. 1). This suggests that $\sigma_{1}$ lies parallel to the plumose axis at the time of fracture propagation.

In situ stress measurements in the Grimsel area revealed high compressive stresses with $S_{H}$ $>S_{h}>S_{v}\left(S_{H}\right.$ : maximum horizontal stress; $S_{h}$ : minimum horizontal stress; $S_{v}$ : vertical stress $)$ within the uppermost few hundred metres below the ground surface [23-25]. Such a stress state supports exfoliation joint formation under high differential principal stresses $[4,21,26,27]$. Based on analyses of directional trends of several hundred exfoliation fracture plumose axes, Ziegler et al. [21] concluded that near-surface principal stress orientations in the Grimsel region are governed by topographic relief, and that maximum principal stresses primarily plunge gently to moderately at differently oriented trough valley slopes (note that we use the term trough valley as a synonym for U-shaped valley).

In order to test the hypothesis that topographic stress perturbation can lead to the previously inferred orientations of near-surface $\sigma_{l}$ and to investigate near-surface stress trajectories in areas not covered by our fractographic dataset, we used three-dimensional, elastic finitedifference models that consider the Grimsel topography. The current and palaeo stress states are the results of superposition of different stress sources (see, e.g., [21] and references therein). We used our models here to evaluate the effect of topographic perturbation on both gravitational stresses and isotropic and anisotropic stresses arising from (active) tectonics 
and/or stresses induced by exhumation. This article illustrates the complexity of near-surface stress orientations, shows that they may follow certain patterns governed by topography, and demonstrates how they can be estimated from fractographic analyses supported by simplified numerical models.

\section{Finite difference in situ stress modelling}

\subsection{Constitutive behaviour, intact rock and rock mass properties}

The rock mass at Grimsel consists mainly of Permo-Carboniferous intrusive rocks, including (from north to south) Mittagfluh Granite, Central Aar Granite (CAGr) and Grimsel Granodiorite (GrGr) of which the CAGr is most widespread (see references cited in [6]). The CAGr is a uniform medium-grained to slightly porphyritic biotite-granite with a massive to foliated structure. The GrGr can be distinguished from CAGr by its larger alkali feldspar augen (up to $2-3 \mathrm{~cm}$ long) and greater amount of dark mica. The granitic and granodioritic rocks are surrounded by the Altkristallin (Ger.), i.e., primarily older, polymetamorphic gneisses and schists. During the Alpine orogeny the rocks of the area underwent ductile to brittle deformation under greenschist facies conditions. Zones of higher ductile strain (gneiss and augen-gneiss) can be distinguished from less deformed areas (granites and granodiorites). The average Alpine foliation in the Grimsel area is oriented 149/77 (dip direction/dip angle).

In this study we strongly simplified the area's geology and assumed a linear-elastic constitutive model for the CAGr in our numerical models, with mean values of elastic properties based on data from the literature (Table 1). The CAGr is dissected by three widespread systematic joint sets with very wide joint spacings on the order of several metres to $>10 \mathrm{~m} \mathrm{[6]}$. Thus, we only slightly reduced the mean Young's modulus of intact rock $\left(E_{i}\right)$ to approximate the Young's modulus of the rock mass $\left(E_{r m}\right)$ used in our modelling. The exact value of $E_{r m}$ is 
irrelevant since we varied far-field strains in the linear elastic numerical models until we received target far-field stresses. In this study we only considered total stresses. Table 1 lists intact rock strength data for the Central Aar Granite and, for comparison, the Grimsel Granodiorite. We investigated the evolving stresses in the elastic models during various loading conditions and compared the final stresses against fracture criteria to identify where extensional-type fracturing may occur (stress path analysis; see, e.g., [32,33]). We applied fracture criteria, based on intact rock strength properties of CAGr, similar to criteria used for predicting spalling around underground openings $[3,34]$ in order to select numerical models where the stress path indicates that fractures nucleate and/or propagate (the fracture criteria are explained in Section 4.1). This allows for later comparison with fractographic data.

\subsection{Model geometry setup}

Our three-dimensional 'block model' represents a rock volume with a height of $13.5 \mathrm{~km}$ (ranging from -10.0 to $3.5 \mathrm{~km}$ above sea level (asl.)), a width of $10.5 \mathrm{~km}$, and a depth of 13.5 $\mathrm{km}$. We set a deep lower model boundary in order to reduce boundary effects influencing near-surface stresses (cf., [35]). In order to establish an approximately realistic current topography, we used the digital terrain model DHM25 by swisstopo. The DHM25 incorporates bathymetric data at the location of storage lakes and has a mean vertical deviation of 3-8 m with respect to ground control points. We deleted artificial dams and lakes located at Lake Räterichsboden, Lake Grimsel, and Lake Gelmer, but did not alter the DHM25 to also expose the bedrock surface in areas occupied by glaciers (e.g., Rhone Glacier) and debris.

Two terrain models with identical dimensions in $\mathrm{x} / \mathrm{x}^{\prime}$ and $\mathrm{y} / \mathrm{y}^{\prime}$ directions and a maximum depth of $10 \mathrm{~km}$ below sea level were developed: the first with model boundaries parallel to the N-S direction $\left(0^{\circ}\right.$-model; Fig. 2$)$, and the second with boundaries rotated anticlockwise by $45^{\circ}$ (45 ${ }^{\circ}$-model; Fig. B.1). The $0^{\circ}$-model and $45^{\circ}$-model overlap by about $82 \%$ (Fig. 3). The 
topography — ranging between about $1.0 \mathrm{~km}$ and $3.5 \mathrm{~km}$ asl. — was created within the block model domain (see above) and all zones above the topography were removed to establish the initial model geometry. To diminish the influence of lateral boundary effects on near-surface stresses in areas of interest, i.e., the trough valley section between Handegg and Lake Grimsel, the target areas were centered in the model domain (Fig. 3). We discretised our models using 7.7 million cubic elements that gradually decrease in size with increasing elevation (Fig. 2; Table 2). Based on morphological constraints and subsurface exposures, such as tunnels, we estimated maximum thicknesses of sediments and glaciers (ice fields) in our models to a few tens of meters. Exceptions to this are at the southern end of the Rhone Glacier ([37] and references therein), where a maximum ice thickness of about $250 \mathrm{~m}$ occurs in the $45^{\circ}$-model, and at the eastern end of the Unteraar Glacier [38], which has an estimated maximum ice thickness of roughly $100 \mathrm{~m}$ in the $0^{\circ}$-model. Both glaciers are located close to model boundaries (Fig. 3).

Ziegler et al. [6] found that exfoliation joints in the study region formed during four distinct episodes in Quaternary time, i.e., exfoliation joints are relatively young compared to steep tectonic joints in the area. The most prominent and wide-spread exfoliation joint generation, i.e., generation 2 , is considered to have formed towards the end of major inner trough valley erosion $(\sim 0.7-0.4 \mathrm{Ma})$, subparallel to Middle Pleistocene palaeo topography. These exfoliation joints dip more gently than the current inner-valley trough smoothed slopes by as much as $20^{\circ}[39,40]$. The Middle Pleistocene palaeo topography was roughly approximated by 'adding elevation' (i.e., rock mass) to the today's terrain altitude and by taking into account erosional constraints (see discussion in [6]). The landscape elevation was gradually increased by $0 \mathrm{~m}$ at mountain peaks and as much as $62.5 \mathrm{~m}$ in valley bottoms, i.e., between 0 and 4 cubic elements of 15.625 m edge length were added (Fig. 2 and Fig. B.1). For comparison with in situ stress data we studied stress tensors in the current topography 
models. For comparison with fractographically inferred palaeo stress orientations we investigated stress tensors a few decametres below the palaeo ground surface (i.e., along the recent topography surface) in the palaeo topography models. This avoided mesh effects caused by the finite difference blocks from influencing near-surface stress tensor results. Fractographic data used in this study come from exfoliation joints that formed during the Middle Pleistocene (generation 2, see above) and Upper Pleistocene (generation 3; [6]). We simplified the problem in this study by using a single palaeo topography and single sampling surface ${ }^{1}$ to obtain 'near-surface' stress estimates for two exfoliation joint generations. We think that this approach is a reasonable first approximation because Ziegler et al. [21] found that overall $\sigma_{1}$ directions inferred from generation 2 and generation 3 exfoliation joints did not decisively change. They argued that this could be because bedrock morphology and topographic stress perturbation, respectively, did not critically change within the last few hundred thousand years in the Grimsel area. This allows us to compare palaeo stress orientations with current in situ stress orientations as well.

\subsection{Initial boundary and gravitational stress conditions}

We investigated loading by gravity until we reached equilibrium conditions ('gravitational stress model', i.e., $S_{H, \text { far-field }}=S_{h, \text { far-field }}=0$ ) using the three-dimensional, finite difference code FLAC $^{3 \mathrm{D}} 5.0$ [41]. Our models are linearly elastic and rock mass properties are assumed to be isotropic (Section 2.1). The basal and vertical boundaries in our gravitational models are 'roller boundaries', i.e., they allow boundary-parallel displacements only and have zero shear traction. The upper boundary (i.e., along topography) is a free boundary. We receive a $k_{S H / S v^{-}}$ value of $\sim 0.43$ for $v_{r m}=0.3$ (the corresponding equations are given in Appendix A). The

\footnotetext{
${ }^{1}$ We sampled model stress data randomly along the current topography $( \pm 5 \mathrm{~m})$ within our palaeo topography models (referred to 'near-surface' stresses in Figs. 4-6, 11, 12, 14, and B.2-B.7). The sampling surfaces in the $0^{\circ}$-models and $45^{\circ}$ models are composed of approximately 0.6 million elements. Thus, we only show a representative selection of modelled stress trajectories in Figs. 4-6, 11, 12, 14, and B.2-B.7.
} 
$k_{S H / S v}$-value describes the ratio of the maximum horizontal stress $\left(S_{H}\right)$ magnitude to the vertical stress $\left(S_{v}\right)$ magnitude.

\subsection{Regional stress field and local in situ stress measurements}

The regional stress (strain) field is not well understood, especially with respect to the regional stress orientations [21]. According to an inversion of GPS data, Tesauro et al. [42] calculated a NW-SE directed supraregional shortening of up to $7 \pm 2$ nanostrain/year for the Alpine chain in Switzerland. GPS stations between $4^{\circ}$ and $16^{\circ}$ longitude move NW with residual velocities, relative to the rotation of the Eurasian plate, ranging between 0.2 and $2.3 \mathrm{~mm} / \mathrm{a}$ (on average $1.0 \mathrm{~mm} / \mathrm{a}$; see also GPS velocity fields presented by Nocquet [43]). NW-SE directed compression is consistent with previous, regional findings [44-46]. In addition, the measured supraregional strain orientation [42] is in agreement with NW directed, deep-seated basal thrusting within this part of the Alps [47]. Burkhard [47] discussed how basal thrusting led to 'updoming' of the Aar Massif during the last $15 \mathrm{Ma}$ and debated if basal thrusting is still ongoing today. Neotectonic activity in form of vertical uplift (up to $\sim 1.5 \mathrm{~mm} / \mathrm{year}$ [48]) might also be "ruled by isostasy/buoyancy forces rather than the ongoing shortening along the Alpine Europe/Adria collision zone" [49]. Earthquake focal mechanisms show that the NW-SE directed first-order stress field changes near the Alps and becomes highly heterogeneous within different tectonic regimes of the central Alps [50-52]. Owing to low seismicity, no data from fault plane solutions exist for the central part of the Aar Massif and the Grimsel area, respectively (see Fig. 2 in Kastrup et al. [52]). In addition, deformation data, e.g., from permanent GPS station measurements, are sparse and the time period of GPS data collection is short within our study region and its surroundings. Thus, the local strain field in the Grimsel area is poorly constrained. Interpretation of seismotectonic data by Delacou et al. [51] suggests NW-SE to WNW-ESE directed compression $\left(\sigma_{1}\right)$, and predominantly strike-slip 
faulting (i.e., $S_{H}>S_{v}>S_{h}$ ) within the deep subsurface of the Grimsel area. The significance of this result is uncertain.

In situ stress measurements in the Grimsel area used hydraulic fracturing and overcoring techniques in subvertical boreholes and were summarized by Ziegler et al. [21]. Thus, we only present an overview of the applied borehole stress measurement techniques and results in Table 3. The reported stress measurements yield information about the local magnitudes and orientations of the horizontal stress components $\left(S_{H}\right.$ and $\left.S_{h}\right)$ and, in the case of the GS 84.041 A borehole at the Grimsel Test Site (GTS), also the magnitude of the vertical stress component $\left(S_{v}\right)$. The significance of stress measurement results from Grimsel-2 and section 2 of the GS 84.041 A, and in particular the orientation of $S_{H}$, is uncertain: Grimsel-2 data are based on 7 doorstopper tests that have been performed between $3.4 \mathrm{~m}$ and $6.5 \mathrm{~m}$ of a $6.7 \mathrm{~m}$ long vertical borehole [55]. The borehole was drilled upwards from a $3.5 \mathrm{~m}$ deep and $3 \mathrm{~m}$ high niche in the Grimsel-2 access gallery of $5.5 \mathrm{~m}$ height and intersected a fracture between $2.9 \mathrm{~m}$ and 3.4 $\mathrm{m}$. Stress perturbations around the gallery may extend 2-3 gallery diameters away from the gallery [56] and, thus, the stress measurements may depart substantially from the far-field stress. Section 2 of the GS 84.041 A borehole ranges from $40 \mathrm{~m}$ to $100 \mathrm{~m}$ along the borehole and is characterised by massive granite and a sparser fracture abundance (mostly 0-2 discontinuities per metre) than borehole sections $1(0-40 \mathrm{~m}), 3(100-170 \mathrm{~m})$, and $4(170-191 \mathrm{~m})$ that yielded mostly $>2-9$ discontinuities per metre in foliated gneiss [24]. Overcoring data from sections 1,3 , and 4 and hydraulic fracturing data from section 4 suggested a mean $S_{H}$ orientation of WNW-ESE. In contrast, overcoring data from section 2 indicated N-S as mean $S_{H}$ orientation. Thus, the in situ stress data from the boreholes Handegg-1, GS 84.041 A (sections 1, 3 and 4), and Kessiturm are regarded as most reliable. 


\subsection{Simulating high, near-surface subhorizontal compressive stresses}

At four locations within the study area high horizontal compressive stresses, considerably larger than the vertical stresses, were inferred from in situ stress measurements [21] (Table 3). We selected four cubic model elements ('observation points') within the model and interpolated the stress tensor components between the nodes for detailed investigation of the stress tensor close to the borehole intervals where in situ stress measurements were conducted (Table 4 and Fig. 3). Since the in situ horizontal and vertical stress components may not represent principal stresses, e.g., owing to topographic stress perturbation, we calculated modelled $S_{v}, S_{h}$, and $S_{H}$ from the full stress tensor at our observation points for comparison with measured in situ stress data.

In order to model high horizontal (far-field) compressive stresses from active tectonics and/or exhumation-induced (remnant) stresses, $S_{H, f a r-f i e l d}$ and $S_{h, f a r-f i e l d}$, we switched two vertical, adjacent external boundaries (i.e., one parallel to the $\mathrm{x}$-/x'-axis, the other parallel to the $\mathrm{y}$ /y'-axis; Fig. 3) of our initial gravitational stress models (Section 2.3) into displacement boundaries and stepwise compressed the model(s) horizontally. The displacements were applied uniformly over these two boundaries. Stress magnitudes and stress orientations in the models were continuously monitored at all nodes as the two boundaries were displaced simultaneously. We varied the boundary displacement rates in such a way as to create 1 . isotropic horizontal strains $\left(\varepsilon_{x x / x x^{\prime}}=\varepsilon_{y y / y y^{\prime}}\right.$; 'isotropic strain model'; $k_{S H / S h, \text { far-field }}=1.0$; Eq. A.11), and 2 . anisotropic horizontal strains $\left(\varepsilon_{x x / x x^{\prime}} \neq \varepsilon_{y y / y y^{\prime}}\right.$; 'anisotropic strain model'). Owing to unequal model dimensions in the $\mathrm{x} / \mathrm{x}^{\prime}-$ and $\mathrm{y} / \mathrm{y}^{\prime}$-direction (10.5 km compared to $\left.13.5 \mathrm{~km}\right)$, we simulated isotropic and anisotropic strains by applying unequal boundary displacements. For ease of reading we always give strains in millistrain (mstrain) or displacements in meter in the direction of the model $y-/ y^{\prime}-a x i s$ if not stated differently. The total amount of horizontal strain was 0.74 mstrain (equals about $10 \mathrm{~m}$ of shortening along the $y-/ y^{\prime}$-axis) in the isotropic strain 
models, and 0.90/0.21 mstrain (i.e., 0.90 mstrain in the $\mathrm{x} / \mathrm{x}^{\prime}$-direction and 0.21 mstrain in y/y'-direction, and vice versa) in the anisotropic strain models. 0.74 mstrain and $0.90 / 0.22$ mstrain equal an additional maximum horizontal stress component of $S_{H, \text { far-field }}=49.6 \mathrm{MPa}$.

Our different alignments of the $0^{\circ}$-model and the $45^{\circ}$-model enable us to 1) test the effect and significance of anisotropic far-field stresses (strains) on near-surface, local stress orientations; 2) investigate the most probable direction of regional stress anisotropy (i.e., N-S, NWSE, W-E, and SW-NE) based on a comparison of recent in situ stress data from boreholes with model calculations at the boreholes; and 3) select the best model for comparison with fractographic indicators of principal stress orientations (i.e., exfoliation fracture plume axes). We identified the best model based on the best fit between measured and modelled $S_{H}$ trends at our observation points (see above and Sections 3.2 and 3.3) and stress magnitudes that are likely to support extensional fracture formation at the near surface (see Section 4.1). Our 'anisotropic strain models' simulate far-field horizontal stresses with $k_{S H / S h \text {, far-field }}=S_{H, f a r}$ field $/ S_{h, \text { far-field }}=2$. For $k_{S H / S h, \text { far-field }}=2$ and $v_{r m}=0.3$ we obtain $\varepsilon_{x x / x x^{\prime}}=4.25 \varepsilon_{y y / y y^{\prime}}$ (the corresponding equations are given in Appendix A). In comparison, the deepest in situ stress measurement results from the Kessiturm borehole [54] and GS 84.041 A borehole [24] at the GTS, which we assume display the smallest stress perturbation by topography in our area, show horizontal (total) stress ratios of 1.84 $\pm 0.1: 1$ (based on 7 measurements between about $320 \mathrm{~m}$ and $570 \mathrm{~m}$ below ground surface (bgs.)) and 1.44 $\pm 0.24: 1$ (based on 28 measurements between about $490 \mathrm{~m}$ and $670 \mathrm{~m}$ bgs.). 


\section{Results}

\subsection{Initial gravitational stress models}

Fig. 4 presents minimum principal stress magnitudes at shallow depth (i.e., within approximately $60 \mathrm{~m}$ below the palaeo topography model surface; see Section 2.2) to illustrate regions with (maximum) tensile stress components (i.e., negative $\sigma_{3}$ values). Minimum principal stresses are compressive (orange and red colours) at the landscape surface of higher elevation and in most parts of the subsurface. Tensile stresses (green and blue colours) developed primarily in the valley bottom of the NNW-SSE directed part of the upper Hasli valley. Tensile stresses are limited to relatively shallow depth below the valley floor (less than about $100 \mathrm{~m}$ bgs.), and their orientations trend about perpendicular to the main valley axis (the orientations of $\sigma_{3}$ are indicated by blue tick marks in Fig. 4). In addition, the Grimsel Pass area and regions of comparably low elevation (i.e., the area around Gletsch/Oberwald in the $0^{\circ}$ model, and the area around Guttannen in the $45^{\circ}$-model (Fig. B.2)) show tensile stresses. In contrast, the WSW-ENE to W-E directed main valley bottom west of Kessiturm does not exhibit tensile stresses.

The $0^{\circ}$-model (Fig. 4) and $45^{\circ}$-model (Fig. B.2) reveal greatest differences in tensile stress distribution close to model boundaries (cf., areas around Guttannen and Gletsch/Oberwald). We attribute these differences to different model topographies at the model boundaries due to model rotation (Fig. 3). Thus, stress estimates close to the model boundaries have to be interpreted with care. However, in the central parts of our models the topographic differences at the model boundaries that arise from model rotation have only a minor effect (compare Fig. 4 with Fig. B.2), and differences in octahedral mean stress, $\sigma_{m}$, at observation points are small (Table 5). They range between approximately $0 \mathrm{MPa}$ at GTS and $0.23 \mathrm{MPa}$ at Handegg-1. This allows us to compare the results from the $0^{\circ}$ - and $45^{\circ}$-models in subsequent modelling 
steps. Our current topography gravitational model results at the GTS are in good agreement $\left(\triangle \sigma_{m}=0.03 \mathrm{MPa}\right.$; Table 5) with modelled principal stresses by Konietzky [36]. As expected, the palaeo topography models show an increase in $\sigma_{m}$ compared to current topography models (Table 5). At our observation points this increase in $\sigma_{m}$ ranges between $0.5 \mathrm{MPa}$ and $1.4 \mathrm{MPa}$. The influence of the topography leads to slope-downward directed (compressive) $\sigma_{l}$ orientations at the near-surface for most of the modelled areas (Fig. 4 and Fig. B.2) and steep to subvertical $\sigma_{l}$ at observations points.

Besides unrealistic tensile stresses in valley bottoms and valley slopes (see discussion in Section 5.1.1), the 'gravitational stress model' results revealed that topographic effects alone cannot explain high compressive stress magnitudes derived from in situ stress measurements (Table 5).

\subsection{Isotropic strain models}

The analysis of stress tensors close to the surface (within approximately $60 \mathrm{~m}$ below the palaeo topography model surface; see Section 2.2) revealed that principal stress orientations change little $\left(<\sim 5^{\circ}\right)$ after $3 \mathrm{~m}$ boundary displacements (corresponding to about 0.22 mstrain) within and close to valley bottoms and close to crest lines. Between lower and higher sections of trough valley slopes and at slopes above the valley 'shoulder' considerable stress rotations $\left(>5^{\circ}\right.$ ) occurred for boundary displacement larger than $3 \mathrm{~m}$ (Fig. 5). The areas between steep inner-valley to more gently inclined upper valley slopes are marked by convex inflexion points in cross-valley profiles and often referred to as inner-valley 'shoulders' (e.g., [6]). In contrast to stress tensors located within the valley bottom and along mountain crests, stress tensors in these 'transition zones' are characterised by similar $\sigma_{1}$ and $\sigma_{2}$ magnitudes $\left(\sigma_{1}\right.$ and $\sigma_{2}$ are subparallel to the ground surface; Fig. 5). 
Fig. 6 and Fig. B.3 present overviews of the $\sigma_{1}$ and $\sigma_{2}$ stress trends and the $\sigma_{1}$ magnitude near the current ground surface at 0.37 mstrain. The $0^{\circ}$ - and $45^{\circ}$-models yield similar results suggesting that the models' sizes are sufficiently large so that local topographic differences can be neglected under isotropic regional loads. Both models show concentration of compressive stresses in the trough valley floors north and west of Grimsel Pass. The $\sigma_{1} / \sigma_{3}$ ratios are mostly $>10$ for depths $\leq 45 \mathrm{~m}$ below the palaeo-topography (Fig. 7A-D) and facilitate exfoliation fracture formation (see Section 4.1). The $\sigma_{1} / \sigma_{3}$ ratios reduce with increasing depths below ground. At the same depth level the $\sigma_{1} / \sigma_{2}$ ratios remain rather constant and are mostly $<3$ (Fig. 7E-H). Maximum compressive stress magnitudes in the main trough valleys are slightly higher in the $0^{\circ}$-model compared to the $45^{\circ}$-model. In both models the maximum principal stress orientations are oriented about perpendicular to valley axes within valley floors and partly up to about the inner-valley trough 'shoulders' (Fig. 6, Fig. B.3). Slope sections at higher altitudes, including mountain ridges, reveal less steeply plunging and subhorizontal orientations of $\sigma_{l}$. These are important differences not found in the initial gravitational models (Fig. 4, Fig. B.2).

With increasing boundary displacement the initially steep plunges of $\sigma_{l}$ become flatter for the selected observation points in the $0^{\circ}$-model (Fig. 8) and the $45^{\circ}$-model (not shown). The changes in principal stress orientations considerably decrease with increasing boundary displacement after about $0.30-0.59$ mstrain (principal stress trends are given by the large black symbols at steps of 0.074 mstrain, small grey dots indicate principal stress rotations at smaller contractional strain increments of 0.37 nstrain). At these strain magnitudes the maximum principal stress orientations at observation points plunge between about $10^{\circ}$ and $15^{\circ}$. Our calculations indicate differences, on the order of tens of degrees, in the trends of modelled $S_{H}$ and $\sigma_{l}$, especially at strains larger than about 0.3 mstrain. Modelled $S_{H}$ trends are marked by pairs of arrows at the perimeters of the plots in Fig. 8. Furthermore, modelled and measured 
$S_{H}$ trends are not in good agreement in models with current topography, except at Grimsel-2 at $<0.44$ mstrain and for section 2 of the GTS GS 84.041 A borehole at $>0.30$ mstrain that both suggest NNW-SSE trending $S_{H}$ orientation (the mean trend of measured $S_{H}$ is given by grey tick marks at the perimeters of the plots, measured $S_{H}$ ranges are indicates by sectors marked in grey). Owing to the close proximity of the site of Grimsel-2 stress measurements to the access gallery and the inconsistency in stress orientations at GS 84.041 A (section 2) the Grimsel-2 and the GS 84.041 A (section 2) stress measurement datasets are considered unreliable and marked with a '?' in Fig. 8 (see Section 2.4).

Fig. 9A-D present the changes of stress magnitudes at observation points as the remote isotropic horizontal strain increases. All locations show an approximately linear increase of $\sigma_{l}$ (curve with long black dashes) and $\sigma_{2}$ (curve with short black dashes) magnitudes with increasing horizontal strains, while the magnitudes of $\sigma_{3}$ (solid black curve) remain relatively constant and are considerably lower. The magnitudes of modelled $\sigma_{3}$ and modelled $S_{v}$ (green dots) are considerably different for observation points GTS, Kessiturm, and Grimsel-2 for models with very low contractional strains ( $<0.07$ mstrain). At larger contractional strains modelled $\sigma_{3}$ and $S_{v}$ have similar magnitudes. In addition, we see that at larger contractional strains the magnitudes of modelled $\sigma_{2}$ and $S_{H}$ (blue dots) are similar. This observation can be explained because 1) the plunges of $\sigma_{2}$ are subhorizontal (i.e., they range between about $0^{\circ}$ and $5^{\circ}$ ) and smaller than those of $\sigma_{1}$ by about $5-10^{\circ}$ (Fig. 8), and 2) the ratios of $\sigma_{1} / \sigma_{3}$ and $\sigma_{2} / \sigma_{3}$ are large (see above). Changes in the ratios of $\sigma_{1} / \sigma_{2}$ remain small $(<10 \%)$ for boundary displacements that yield regional contractional strains greater than 0.37 mstrain. In contrast, $S_{H} / S_{h}$ ratios $\left(k_{S H / S h}\right)$ increase with strains $>0.37$ mstrain, except for Grimsel-2 where $k_{S H / S h}$ remains almost constant. Comparison of modelled horizontal stress magnitudes with in situ stress measurement results reveals that at GTS a model boundary displacement that yields a regional contraction of about 0.46 mstrain results in $S_{H}, S_{h}$, and $S_{v}$ magnitudes similar to the 
measured mean in situ stress components. In contrast, observation points at Handegg-1 and Grimsel-2 yield comparable (maximum) horizontal and vertical stress magnitudes at lower strains of approximately 0.13 mstrain and 0.15 mstrain, respectively. The reported $S_{H}$ and $S_{h}$ magnitudes at Grimsel-2 might be too low since a low Young's modulus of $19.2 \mathrm{GPa}$ for GrGr [Table 3; 55], compared to 50-64 GPa for GrGr at Kessiturm (see Table 1; [29]), was used for the stress calculations. Assuming that the measured horizontal stress components at Grimsel-2 were underestimated by a factor of about 2 or more, modelled $k_{S H / S h}(\sim 1.14-1.17)$ and measured $k_{S H / S h}(1.15)$ would be about similar in the isotropic strain model. At Kessiturm no model deformation state can be identified that would be close to the in situ horizontal stress ratio at comparable horizontal stress magnitudes.

Isotropic strain models showed that the maximum horizontal stress orientations at observation points are not consistent with the most reliable stress measurement results, i.e., from the GTS (GS 84.041A sections 1, 3, and 4), Kessiturm, and Handegg-1. Furthermore, the modelled horizontal stress ratio at Kessiturm was too low (1.04 vs. in situ 1.84; see Section 2.5) at a target $S_{H}$ magnitude of about $27 \mathrm{MPa}$.

\subsection{Anisotropic strain models}

In an effort to fit the model results better to the stress measurements, we tested anisotropic straining with $k_{S H / S h \text {, far-field }}=2.0$ in four directions (i.e., N-S, W-E, NW-SE, and SW-NE). Models simulating maximum contraction in W-E (Fig. B.4) and NW-SE directions (Fig. B.5) yield better results for $S_{H}$ trends than models with isotropic horizontal straining. Our $0^{\circ}$-model with W-E-oriented maximum straining and $k_{S H / S h}$, far-field $=2.0$ matches best with measured data (i.e., stress orientations and magnitudes, and horizontal stress ratios shown in Table 6). In contrast, models with maximum strains in N-S (Fig. B.6) and NE-SW (Fig. B.7) directions are not consistent with measured data. Fig. 10 shows the results from the $0^{\circ}$-model with W-E- 
oriented maximum contraction. Modelled trends of $S_{H}$ are represented by pairs of arrows at the perimeters of the plots, the one standard deviation range $(1 \sigma)$ and mean value of measured trends of $S_{H}$ are given by the grey sectors and the grey tick marks at the perimeters of the plots. The plots illustrate that modelled and measured $S_{H}$ trends at Handegg-1, GTS (GS 84.041A sections 1,3 , and 4), and Kessiturm and the trends of modelled $S_{H}$ and $\sigma_{l}$ (marked by black squares) match better with each other in contrast to the isotropic straining results (Fig. 8). Modelled horizontal stress magnitudes are within $1 \sigma$ of the measurements at Handegg-1 at $\sim 0.22$ mstrain (strains are given in the W-E direction; cf., Eq. A.4), at GTS at $\sim 0.58-0.90$ mstrain, and at Kessiturm at $\sim 0.40-0.54$ mstrain (Fig. 9E-G; compare the $1 \sigma$-ranges of measured $S_{H}$ and $S_{h}$, indicated by blue and orange colored bands, with blue and orange dots representing modelled $S_{H}$ and $\left.S_{h}\right)$. At Grimsel-2 the modelled horizontal stress ratio ( 1.35) is larger than the measured ratio (1.15) at $\sim 0.25$ mstrain, where modelled and measured maximum horizontal stresses are of similar magnitude (Fig. 9H; see also comment on Grimsel-2 stress data in Section 3.2). A similar behaviour was observed in the isotropic strain model case for low strain magnitudes (Fig. 9D). In summary, modelled stress magnitudes that are consistent with measured data are found at different regional strains for different observation points.

The $\sigma_{1} / \sigma_{3}$ ratios in the model with $\mathrm{W}$-E directed maximum contractional strain are mostly > 10 for depths $\leq 45 \mathrm{~m}$ below the palaeo-topography and reduce with increasing depths below ground (Fig. 7I-L). The $\sigma_{1} / \sigma_{3}$ ratios are very similar compared to the isotropic contractional strain model (Fig. 7A-D). The $\sigma_{1} / \sigma_{2}$ ratios range mostly between 1.5 and 3.5 (Fig. 7M-P) and are, as expected, larger compared to the isotropic contractional strain model (Fig. 7E-H). 


\section{Comparison of modelled $\sigma_{1}$ orientations with exfoliation joint plume axes}

\subsection{Numerical model selection}

In this section we first present the fracture mechanical basis and thresholds for the formation of extensile exfoliation fractures that we used. In a previous study the formation of exfoliation fractures was investigated in great detail using fractographic field observations [21]. We applied three criteria (crack initiation stress level, principal stress ratio, and fit with measured stresses) to the models presented in Sections 3.2 and 3.3 to select two models, i.e., one with isotropic and one with anisotropic contractional straining, that we used for the comparison with the fractographic data.

Observation point Handegg-1 is located within an exfoliated rock mass [6]. Exfoliation joints are thought to form as mode I extensional fractures, rather than as Coulomb shear fractures (e.g., Ziegler el al. [21]). The stress magnitudes at which exfoliation fractures form are not well understood. According to the 'tri-linear failure envelope' proposed by Diederichs [32], onset of extensional fractures is primarily dependent on the generation of sufficient stress to overcome the crack initiation threshold, $c_{i}$ (cf., $\left.[27,58]\right)$. Crack initiation is defined as the stress level where stable microcracks with sizes up to about the rock's grain size originate from existing microscopic flaws. In intact, low-porosity rocks $c_{i}$ lies at about $30-50 \%$ of the intact unconfined compressive strength (UCS) [33,59-61]. Once sufficient damage has accumulated microcracks are able to coalesce and develop into unstable, macroscopic fractures. In short-term experiments this damage stress level lies at about $70-80 \%$ of the UCS $[33,60]$. As discussed by Bucher and Loew [62], Leith et al. [8,63], and references therein, a low confinement with a ratio of $\sigma_{1} / \sigma_{3}$ greater than about 10-20 is needed for extensional fracture (exfoliation joint) formation, consistent with the so-called 'spalling limit' that can be used to pre- 
dict the rock mass behaviour in the low confining stress range around underground openings in massive rock mass at great depths (see Fig. 24 in Diederichs et al. [32]).

The long-term rock strength may be estimated best by using the crack-initiation threshold [32]. Further considerations may include time-dependent (i.e., subcritical) fracture growth. Laboratory and field studies (i.e., fractographic analyses) indicate that subcritical fracture growth may play an important role in exfoliation joint formation $[21,58,64-66]$. Timedependent fracture propagation can be attributed to, e.g., stress corrosion $[67,68]$. In addition, fatigue [69] and creep [70] are also among subcritical phenomena. At low fracture stresses, environmental conditions can lead to rock strength degradation around the fracture tip, with the degree of water saturation controlling fracture propagation [66,70-73]. The aforementioned crack initiation stress may, thus, not represent the absolute lowest limit of the longterm rock strength. Presumably below a certain subcritical stress threshold no crack growth occurs [67]. Based on interpretation of short-term creep test results, stress corrosion numerical models, plate tectonics, and in situ rock stress observations, Damjanac and Fairhurst [74] provide evidence that a long-term deviatoric stress threshold exists for crystalline rocks such as granites, and that "this threshold is likely to be a significant proportion of the crack initiation stress $[.]$.$" .$

Considering $c_{i}$ as being in the range of $30-50 \%$ of UCS for Central Aar Granite (CAGr) translates to a magnitude of $c_{i}$ equal to about 50-85 MPa for mean UCS values of CAGr (Table 1). Such stresses are reached in shallow rock mass of inner-trough valley floors at approximately $0.3-0.6$ mstrain in our models with isotropic straining, and at approximately $0.4-$ 0.6 mstrain (along x-axis) in models with anisotropic straining with maximum strains oriented W-E. The latter models show considerably smaller compressive stress concentrations in the large W-E trending valley near Lake Grimsel than in the N-S trending valley segment north of 
Handegg (cf., Fig. B.4). For comparison, $c_{i}$ of Grimsel Granodiorite ranges from $52 \mathrm{MPa}$ to $93 \mathrm{MPa}$ (Table 1). This is a similar magnitude range as suggested above for CAGr.

For subsequent analyses we used the $0^{\circ}$-model with isotropic strains of 0.37 mstrain (referring to $S_{H, \text { far-field }}=S_{h, \text { far-field }}=24.8 \mathrm{MPa}$ ) and with anisotropic strains of 0.45 mstrain in W-E orientation and 0.11 mstrain in N-S orientation (referring to $S_{H, \text { far-field }}=2 \cdot S_{h, \text { far-field }}=24.8$ $M P a)$. We selected these models based on following criteria:

1. Stresses in inner valley floors and adjacent slopes along the sampling surface yield differential stresses $\left(\sigma_{1}-\sigma_{3}\right)$ generally ranging between the lower and upper bounds of $c_{i}$ in the isotropic strain models (Fig. 6 and Fig. B.3). Changes in principal stress orientations at smaller and larger strains were shown to be relatively low in most of the area of interest, i.e., within the extent of inner-trough valleys (Fig. 5).

2. $\sigma_{1} / \sigma_{3}$ ratios close to the model surface in the vicinity of inner valleys are mostly above 10 for the selected models (Fig. 7A-C and Fig. 7I-K). Such large differential stresses are assumed to be a necessary prerequisite for exfoliation fracture formation.

3. The models with isotropic and anisotropic straining allow us to investigate the influence of regional anisotropic horizontal stress (strain) on near-surface maximum principal stress orientations. As discussed in Section 3.3, W-E-oriented maximum anisotropic strain yielded a better fit than isotropic models for $S_{H}$ data inferred from in situ stress measurements in boreholes.

\subsection{Comparison of $\sigma_{l}$ orientations}

In general, the numerically modelled and fractographically inferred data sets reveal complex patterns of stress orientations that follow similar trends. Fig. 11 shows modelled stress trajectories in the area surrounding Lake Räterichsboden (A: isotropic straining, B: anisotropic straining; for location see Fig. 3). Regional (km-scale) and local (on the order of few 
hundred metres) trends of modelled $\sigma_{1}$ are in reasonable agreement with $\sigma_{1}$ trends inferred from plumose structure axes (166 plumose axis measurements). Close to the Aar valley bottom the general trend of fractographically derived $\sigma_{l}$ is about perpendicular to the valley axis and supported by both models (location B). The isotropic strain model shows moderately steep to subhorizontal $\sigma_{l}$ plunges at higher and steeper parts of trough valley slopes (Fig. 11A; note that modelled $\sigma_{1}$ and $\sigma_{2}$ are about parallel to the modelled palaeo surface). This stress rotation is less pronounced in the anisotropic strain model (Fig. 11B). Fig. 12 (detail A) shows a series of 60 plumose axes measured in the field and compares their trends with modelled $\sigma_{1}$ trajectories (A: isotropic straining, B: anisotropic straining). Fig. 13A and Fig. 13B show histograms of the angular differences between individual plume axes and modelled $\sigma_{l}$ orientations in bins of $15^{\circ}$ (A: north of Lake Räterichsboden; B: location A north of Lake Räterichsboden). Overall, the $\sigma_{l}$ trajectories in the isotropic strain model (see black bars in Fig. 13A and Fig. 13B) match with fractographic data around Lake Räterichsboden better than in the anisotropic strain model (see grey bars in Fig. 13A and Fig. 13B). However, both models show that the majority of angular differences between fractographically-inferred and modelled $\sigma_{l}$ orientations north of Lake Räterichsboden is smaller or considerably smaller than $45^{\circ}$. For location $\mathrm{A}$ in the isotropic model, $83 \%$ of the data show angular differences $<45^{\circ}$ $\left(73 \%\right.$ are $<30^{\circ}$; Fig. 13B). Less consistent or contradictory stress orientations with an angular difference $>45^{\circ}$ are also evident. These can be seen, e.g., at location C and D in Fig. 11. Modelled orientations of $\sigma_{1}$ south of Lake Grimsel and west of Kessiturm show a sharp transition at about 2000-2100 m asl. in the isotropic strain model (Fig. 14A). This transition is characterised by NNW-SSE trends of $\sigma_{l}$ near the valley floor and approximately WSW-ENE trends of $\sigma_{1}$ at trough valley slopes and the inner-valley shoulder at higher altitudes. Plume axes (23 measurements) located within and slightly above this transition zone suggest on average a subhorizontal WSW-ENE orientation for the maximum principal stress. Fig. 14B 
shows the model results for anisotropic regional strain with the maximum strain aligned W-E. Here, the aforementioned transition is less sharp than in the isotropic strain model and $\sigma_{l}$ trajectories trend towards WNW-ESE, compared to WSW-ENE in the isotropic model, at the locations of measured plume axes. The anisotropic strain model yields a poor fit between modelled and measured $\sigma_{1}$ orientations west and east of Kessiturm (61\% of the data suggest angular differences $<45^{\circ}$; see grey bars in Fig. $13 \mathrm{C}$ and the discussion in Section 5.2). No fit between modelled and measured $\sigma_{1}$ orientations was obtained with the isotropic strain model $\left(39 \%<45^{\circ}\right.$; see black bars in Fig. 13C).

\section{Discussion}

\subsection{Model sensitivity and confirmation of model assumptions}

\subsubsection{Observations from initial gravitational models}

The development of tensile stresses in parts of main valley bottoms of our models are consistent with results obtained from two-dimensional analytical and numerical models omitting or neglecting active tectonics or remnant stresses $[35,75,76])$. Compressive stresses in the valley floor west of Kessiturm may be attributed to its considerably higher elevation compared to the NNW-SSE oriented, deeper valley south of Grimsel Pass. Mountains exert more downwards-directed force compared to valleys and, thus, can lead to bending and tensile strains in the shallow subsurface of valley floors. However, tensile stresses stand in contrast to observations made in the Grimsel region. At Handegg-1 (Fig. 3), located within the valley bottom, high near-surface compressive stresses have been encountered in the tested borehole sections (44-77 m bgs.; Table 3) and suggest that the rock mass above the tested intervals is likely under high compressive stresses. Intact rock mass failure, such as spalling during excavation of subsurface galleries near Handegg [77] and minor rock bursts [78] further support 
high compressive stresses, i.e., $k_{S H / S v}>>1$ at shallow depth. Tensile stress concentrations in the shallow subsurface along valley floors are inconsistent with field observations in the Grimsel region since these do not show steep (open) fractures located in valley bottoms and aligned subparallel to valley axes (assuming zero long-term rock mass tensile strength; cf., [79] and references cited in [80]). Furthermore, compressive tectonic regimes are thought to prevail over large part of the European and world-wide continental crust $[14,57,81]$. Primarily slope-downward directed (compressive) maximum principal stress trends are in agreement with analytical results obtained by Liu and Zoback [17]. They found that gravitational stresses (assuming a lithostatic stress state, i.e., $k=1$ ), caused by a three-dimensional, elongated ridge of $1 \mathrm{~km}$ height above a flat plane at zero elevation, leads to maximum compressive stresses about perpendicular to the ridge axis below most of the ridge at a depth of $-1 \mathrm{~km}$. In addition, our gravitational stress model results are in good agreement with numeric model results obtained by Konietzky [36]. The study by Konietzky [36] is based on a three-dimensional distinct element model with horizontal dimensions of $10.0 \mathrm{~km} \times 8.5 \mathrm{~km}$, a maximum height of $6.24 \mathrm{~km}$, rock mass density of $2700 \mathrm{~kg} / \mathrm{m}^{3}$, Poisson's ratio of 0.33 , and gravitational acceleration of $9.81 \mathrm{~m} / \mathrm{s}^{2}$. His model included nine discontinuities of which eight dip steeply (between $66^{\circ}$ and $\left.78^{\circ}\right)$ to $\mathrm{SE}\left(144^{\circ}\right)$ and represent major, cohesion-less fault zones occurring in the vicinity of the GTS. The footprint of the modelled region is given in Fig. 3. The model's longest horizontal axis is directed $\mathrm{N} 45 \mathrm{~W}$ (as in our $45^{\circ}$-model) and the modelled area overlaps considerably with our $45^{\circ}$-model. Despite a relatively rough representation of topography, using a triangulated surface model with element edge lengths up to several hundred metres, and representation of discontinuities, principal stresses at point L230, which is closest to our observation point GTS, are similar in magnitudes and orientations (Table 5; Fig. 8B).

The gravitational stress models illustrated that topographic perturbation can have a strong influence on the ratios between $\sigma_{1}$ and $\sigma_{2}$, and $S_{H}$ and $S_{h}$, respectively (Table 5; Fig. 4 and Fig. 
B.2). Unequal $\sigma_{1}$ and $\sigma_{2}$ magnitudes are supported by elongated plumose structure shapes. However, gravitational stress magnitudes are far below in situ stress magnitudes inferred from borehole tests, and modelled $\sigma_{l}$ plunge downslope, in contrast to $\sigma_{1}$ inferred from plumose axes. Thus, models that account only for gravity and omit the effects of, e.g., horizontal tectonic stresses or remnant horizontal stresses due to erosional unloading, cannot explain local observations of exfoliation (sheeting) joints and stress data.

\subsubsection{Strain magnitude}

Model boundary displacements aimed to roughly approximate lateral tectonic shortening, in order to generate horizontal regional compressive stresses greater than would arise under gravitational stresses and lateral confinement, and/or excess lateral compressive stresses caused by uplift and erosion. Apart from topographic stress perturbation [14,69,75], lateral tectonic shortening [82-85] and the elastic response of laterally confined rock mass to erosional unloading [26,86-88] are considered primary causes for high compressive, near-surface stresses with $k_{S H / S h}>1$, i.e., reverse faulting conditions, in the Grimsel area.

Stepwise isotropic lateral contractional straining of gravitational models showed that different locations, such as valley bottoms, steep trough valley slopes, less steep upper valley slopes, and mountain crests respond differently to horizontal strains. Concave morphologies, such as valleys, act as stress concentrators (e.g., [80]) and small contractional strains (on the order of 0.07 mstrain) were needed to render most of the modelled volume and especially valley floors compressive. For detailed analysis of near-surface stress trajectories in models simulating isotropic straining we used 0.37 mstrain, keeping most of the modelled area below or within a typical range of microcrack initiation close to the ground surface.

Various data from the Grimsel region support differential rock stresses with high surfaceparallel compressive stresses in comparison to surface-normal stresses at depths of at least few hundred meters below ground. The data include in situ stress measurement results from 
four sites (Handegg-1, GTS, Grimsel-2, and Kessiturm; Table 3), stress-induced intact rock failure (i.e., spalling) of shallow subsurface gallery walls [89], an explosion-like rock burst at the landscape surface at Handegg [78], and widespread occurrence of exfoliation fractures. We showed that further straining above 0.37 mstrain has only little effect on the trend of $\sigma_{1}$ near the landscape surface in the area of primary interest, i.e., within the inner-valley troughs (Fig. 5). Thus, our 0.37 mstrain model proved to be robust for analysing $\sigma_{1}$ trajectories near the landscape surface and comparing these with fractographically-derived and in situ measured stress trends.

Fig. 15 illustrates analytical results of the changes of $k_{S H / S v}$ (thick black line) and $k_{S h / S v}$ (pointed grey line) with depth for a virtual model with no topographic relief (i.e., horizontal upper model surface) and with the selected isotropic and anisotropic model strains (see model selection criteria in Section 4.1 and equations presented in Appendix A). These analytically derived curves are shown together with in situ data from borehole stress measurements (filled rhombic, triangular, circular, and square symbols) and results at observation points from models with current topography (numerically modelled $k$-ranges are indicated by blue and red arrows pointing towards larger contractional model strains; marker symbols indicate $k$-values for our anisotropic model with maximum contractional strain of 0.45 mstrain directed W-E). Except for two data points from the GTS (circular symbols) and Kessiturm (triangular symbols) boreholes, the in situ stress data show that $k_{S H / S v}$ and $k_{S h / S v}$ are greater than 1 and that greatest $k$-values occur at the most shallow depths at Handegg-1 (rhombic symbols). Despite local differences in $k_{S H / S v}$ and $k_{S h / S v}$ from in situ measurements, likely originating from different depth and stress perturbation along boreholes (owing to structural (rock foliation, fractures) and lithological rock mass heterogeneity (e.g., dykes)), the comparison of modelled and in situ data reveals considerable overlaps and further supports the strain magnitudes used for stress tensor analysis at the near-surface (i.e., 0.37 mstrain for the isotropic strain model and 
0.45 mstrain in W-E direction for the anisotropic strain model). As a consequence of homogeneous strains applied over the entire vertical boundaries, $k_{S H / S h}$ decreases with increasing depth below ground. For shallow rock mass $(<100 \mathrm{~m}$ bgs.) in our virtual model with no topographic relief $k_{S H / S h}$ ranges between about 1.92 and 2 and decreases to about 1.62 at a depth of $680 \mathrm{~m} \mathrm{bgs.}$, close to the depth of the deepest stress measurements at the Grimsel Test Site (cf., Section 2.5). The topographic effect on $k_{S H / S v^{-}}$and $k_{S h / S v^{-}}$values for the deepest three observation points is low. The $k_{S H / S v^{-}}$and $k_{S h / S v^{-}}$-values at Grimsel-2 (square symbols), Kessiturm, and GTS cluster about expected $k$-values from the virtual model with no topographic relief. In contrast, numerically modelled (and measured) $k$-values from Handegg-1, located in shallow ground of the valley floor, are considerably smaller than the predicted $k$-values from the virtual model with no topographic relief.

As described in Section 2.4, interpolation of earthquake focal mechanisms [51] suggests strike-slip faulting for the deeper subsurface of our study region. The focal mechanisms used by Delacou et al. [51] originate from earthquakes with hypocentre depths ranging between 0.5-30 km bgs. (cf., earthquake hypocentres in the central Aar Massif locate at depths roughly up to $15 \mathrm{~km}$ bgs. [90]). At depth <700 m only two stress measurement data points support strike-slip faulting as mentioned above. However, our virtual anisotropic strain model with no topographic relief yields strike-slip faulting (and transitional stress regimes [81]) between about 0.8 and $1.65 \mathrm{~km}$ bgs. (Fig. 15), to some extent supporting the results by Delacou et al. [51]. Below $1.65 \mathrm{~km}$ our models show normal faulting. This is because we assumed constant contractional horizontal strains with increasing depth.

\subsection{Near-surface principal stress orientations}

As a first approximation we analysed models with both gravitational stresses and additional isotropic horizontal far-field contractional strains of 0.37 mstrain, and compared modelled 
stresses with in situ stresses from borehole tests and palaeostress data inferred from exfoliation joint plumose axes. Our $0^{\circ}$ - and $45^{\circ}$-model results show $\sigma_{1}$ trajectories with complex patterns with $\sigma_{3}$ oriented about perpendicular to the landscape surface at shallow depths, a prerequisite for opening-mode fracture formation parallel to bedrock surfaces. Valley floors exhibit compressive stresses and $\sigma_{l}$ orientations about perpendicular to valley axes (Fig. 6). This has been described previously by other researchers utilising two-dimensional models of crossvalley profiles (e.g., [8,14,91]; cf., [92]) and is to a certain extent analogous to well-studied compressive stress concentrations around boreholes and larger subsurface openings, such as tunnels [93-96]. The majority of plumose structure axes close to the valley bottom north of Lake Räterichsboden is aligned about perpendicular to the valley axis; this finding supports our modelled $\sigma_{1}$ trajectories (Fig. 11A, detail B). At steep slopes of inner-valley troughs, away from valley floors, modelled $\sigma_{1}$ trajectories rotate and, in places, are aligned subparallel to topographic contours (see, e.g., the slopes south of Lake Grimsel in Fig. 14A). As a consequence of this stress rotation, certain sections of inner-valley slopes contain locations where $\sigma_{1}$ and $\sigma_{2}$ are similar in magnitude (see 'transition zones' in Section 3.2). In our models these areas are located below or close to the inner-valley shoulder. Our previous fractographic analysis of plumose structure axes of exfoliation joints supports such stress rotation. The pitch angles of plume axes decrease from valley floors to inner-valley trough shoulders (see definition of pitch angle in Fig. 1 and [21]). We find good agreement between the fractographic dataset and isotropic strain model results around Lake Räterichsboden (Fig. 11A, Fig. 12A, Fig. 13A, and Fig. 13B). Mismatch between modelled and fractographically inferred $\sigma_{1}$ trends, such as at locations $\mathrm{C}$ and D in Fig. 11A and in Fig. 14A may be attributed to: 1) modelled stress tensors with similar magnitudes of $\sigma_{1}$ and $\sigma_{2}$ that are highly sensitive to the magnitude of far-field straining (Fig. 5); 2) current (small-scale) and palaeo morphological forms not covered in the numerical models that may have led to the measured, fractographically 
inferred variation in palaeostress orientations (at small scales); 3) fractographically inferred $\sigma_{1}$ trends that may be influenced locally by stress perturbation of various causes not included in the numerical model (e.g., stress heterogeneities associated with shear dislocations along surrounding faults, and structurally controlled rock stresses reflecting, for example, rock elastic anisotropy and rock mass heterogeneity; see, e.g., [2,80]); and 4) the assumption of isotropic far-field strains.

In order to address the latter point we simulated anisotropic regional strain (see Sections 2.5 and 5.1.2). We found that the model with a maximum strain directed W-E revealed better matches between 1) $S_{H}$ trends at observation points (Fig. 10), 2) $k_{S H / S h}$-values at observation points GTS (borehole section 1) and Kessiturm (Table 6), and 3) modelled and fractographic results (Fig. 14B), compared to the isotropic strain model. The model with NW-SE directed maximum strain showed less improvements than the model with W-E directed maximum strain. With few local exceptions and considering all observations (i.e., exfoliation joint plumes and in situ stress data), SW-NE and N-S directed maximum strain models led to bigger disagreements between the different datasets. These results suggest W-E to NW-SE directed anisotropic, far-field compressive stresses (contractional straining) as best estimate for the regional stress (strain) direction. This finding supports WNW-ESE to NW-SE oriented compressive stresses as interpolated from earthquake focal plane solutions [51] (see Section 2.4) and W-E to WNW-ESE oriented palaeo compression inferred from dextral (striking $070^{\circ}$ ) and sinistral (striking $120-130^{\circ}$ ) strike-slip brittle faults [97] identified in the Grimsel region.

Besides anisotropic contractional strains (anisotropic far-field lateral compressive stresses), rock and rock mass anisotropy may facilitate WSW-ENE oriented maximum principal stresses as inferred from exfoliation fracture plumes south of Lake Grimsel. The rock mass south of Lake Räterichsboden is composed of granodioritic gneisses and schists with mean 
Alpine foliation, and associated foliation-parallel fractures, dipping steeply $\left(>70^{\circ}\right)$ to $\mathrm{SE}-\mathrm{SSE}$ $[6,39,98]$. Such rock masses are known for anisotropic mechanical behaviour and may influence rock mass stress orientations in the southern parts of our model area. Rock mass anisotropy is a likely cause for the poor fit of the $\sigma_{l}$ trends between our anisotropic strain model and the fractographic data south of Lake Grimsel. Furthermore, brittle-ductile faults with trace lengths of several kilometres truncate the Grimsel rock mass [97,99]. It is conceivable that, besides strong topographic control on near-surface stresses and rock fabric, these large-scale faults led to local stress variations within different rock mass compartments [85,100].

\section{Conclusions}

Our numerical calculations support our hypothesis that exfoliation joint plumose axes follow maximum principal palaeostress trajectories and can be used as cheap and widespread stress indicators. Three-dimensional, elastic finite difference models illustrated that small horizontal compressive strains, simulating active tectonic and/or exhumation-induced stresses, lead to considerable stress changes within valley floors of the Grimsel region, i.e., from tensile to compressive stresses. While pure gravitational loading caused predominantly downslope oriented, maximum compressive principal stresses $\left(\sigma_{1}\right)$ at slopes, superposition of gravitational and horizontal far-field stresses resulted in a stress rotation within slopes. This rotation is characterised by a transition from downslope oriented $\sigma_{l}$ trajectories near valley bottoms up to subhorizontally oriented $\sigma_{l}$ trajectories at higher slope sections up to the mountain crests. Modelled and fractographically inferred, near-surface $\sigma_{l}$ trends are in reasonable agreement at a regional scale. Anisotropic strain models with maximum strain oriented W-E led to improved conformity between different data sets (i.e., in situ stress measurements and fractographic data south of Lake Grimsel) and modelled stresses. 
We have shown in this paper that 1 . novel integration of in situ stress data, fractographically inferred stress orientations, and simplified numerical models can be used to estimate near-surface principal stress trends even within areas of complex topography, such as the Grimsel region, and 2. that the topography and supplemental horizontal (e.g., tectonic) stresses are the main drivers for the fractographically identified stress pattern.

Our models demonstrate large variations of stress orientations, which cannot be captured by small numbers of classical stress measurements. The integration of local stress measurements, fractographic analysis and numerical models allow us to predict the variations in stress orientation for large surface areas and rock volumes. Even though the modelled stress magnitudes are not well constrained, our approach substantially contributes to the identification of areas that are prone to compressive stress concentrations and potentially problematic ground conditions.

\section{Acknowledgements}

This research is part of the Paraglacial Rock Slope Mechanics project supported by the Swiss National Science Foundation (SNF 135184). We thank KWO Kraftwerke Oberhasli AG, Innertkirchen, for providing stress measurement data. Prof. Benoît Valley (Université de Neuchâtel) provided valuable feedback on an early version of this manuscript. We gratefully acknowledge the constructive comments from two anonymous reviewers that improved our manuscript.

\section{References}

[1] Amadei B, Stephansson O. Rock stress and its measurement. London: Chapman \& Hall; 1997. 
[2] Zang A, Stephansson O. Stress field of the earth's crust. Dordrecht: Springer; 2010.

[3] Martin CD, Read RS, Martino JB. Observations of brittle failure around a circular test tunnel. Int. J. Rock Mech. Min. Sci. \& Geomech. Abstr. 1997; 34(7):1065-73.

[4] Dale TN. The commercial granites of New England. Washington: Government Printing Office; 1923.

[5] Jahns RH. Sheet structure in granites: its origin and use as a measure of glacial erosion in New England. J. Geol. 1943; 51(2):71-98.

[6] Ziegler M, Loew S, Moore JR. Distribution and inferred age of exfoliation joints in the Aar Granite of the central Swiss Alps and relationship to Quaternary landscape evolution. Geomorphology 2013; 201:344-62.

[7] Leith K, Moore JR, Amann, F., Loew, S. In situ stress control on micro-crack generation and macroscopic extensional fracture in exhuming bedrock. J. Geophys. Res. (Solid Earth) 2014; 119(1):594-615.

[8] Leith K, Moore JR, Amann F, Loew S. Subglacial extensional fracture development and implications for Alpine Valley evolution. J. Geophys. Res. (Earth Surface) 2014; 119(1):62-81.

[9] Hoek E. Big tunnels in bad rock: 2000 Terzaghi Lecture. J. Geotech. Geoenviron. Eng. 2001; 127(9).

[10] Heim A. Untersuchungen über den Mechanismus der Gebirgsbildung im Anschluss an die geologische Monographie der Tödi-Windgällen-Gruppe: Band 2: Allgemeine Untersuchungen über den Mechanismus der Gebirgsbildung. Basel: Benno Schwabe; 1878. 
[11] Barton N, By TL, Chryssanthakis P, Tunbridge L, Kristiansen J, Løset F et al. Predicted and measured performance of the $62 \mathrm{~m}$ span Norwegian olympic ice hockey cavern at Gjøvik. Int. J. Rock Mech. Min. Sci. \& Geomech. Abstr. 1994; 31(6):617-41.

[12] Leith W. Geologic and engineering constraints on the feasibility of clandestine nuclear testing by decoupling in large underground cavities. Open File Report 01-28. Reston, Virginia: U.S. Geological Survey; 2001.

[13] Savage WZ, Swolfs HS. Tectonic and gravitational stress in long symmetric ridges and valleys. J. Geophys. Res. 1986; 91(B3):3677-85.

[14] Miller DJ, Dunne T. Topographic perturbations of regional stresses and consequent bedrock fracturing. J. Geophys. Res. 1996; 101(B11):25523-36.

[15] Hasebe N, Wang X. Irregular elastic half-plane gravity problem. Int. J. Rock Mech. Min. Sci. \& Geomech. Abstr. 2003; 40:863-75.

[16] Kinakin D, Stead D. Analysis of the distributions of stress in natural ridge forms: implications for the deformation mechanisms of rock slopes and the formation of sackung. Geomorphology 2005; 65:85-100.

[17] Liu L, Zoback M. The effect of topography on the state of stress in the crust: application to the site of the Cajon Pass Scientific Drilling Project. J. Geophys. Res. 1992; 97(B4):5095-108.

[18] Savage WZ. Topographic stress perturbations in southern Davis Mountains, west Texas: 1. Polarity reversal of principal stresses. J. Geophys. Res. 2002; 107(B12), doi:10.1029/2001JB000484. 
[19] Figueiredo B, Cornet FH, Lamas L, Muralha J. Determination of the stress field in a mountainous granite rock mass. Int. J. Rock Mech. Min. Sci. \& Geomech. Abstr. 2014; $72: 37-48$

[20] Clair JS, Moon S, Holbrook WS, Perron JT, Riebe CS, Martel SJ et al. Geophysical imaging reveals topographic stress control of bedrock weathering. Science reports 2015; 350(6260):534-538.

[21] Ziegler M, Loew S, Bahat D. Growth of exfoliation joints and near-surface stress orientations inferred from fractographic markings observed in the upper Aar valley (Swiss Alps). Tectonophysics 2014; 626:1-20.

[22] Kulander BR, Dean SL. Hackle plume geometry and joint propagation dynamics. In: Stephansson O, editor. Fundamentals of rock joints: Proceedings of the International Symposium on Fundamentals of Rock Joints, Björkliden, 15-20 September 1985. Luleå: Centek; 1985, p. 85-94.

[23] Pahl A, Bräuer V, Heusermann S, Kilger B, Liedtke L. Results of engineering geological research in granite. Bull. Int. Assoc. Eng. Geol. 1986; 34:59-65.

[24] Pahl A, Heusermann S, Bräuer V, Glöggler W. Grimsel Test Site: Rock stress investigations. Technical Report 88-39E. Baden: Nationale Genossenschaft für die Lagerung radioaktiver Abfälle (Nagra); 1989.

[25] Konietzky H, Marschall P. Excavation disturbed zone around tunnels in fractured rock - Example from the Grimsel Test Site. In: Rakowski Z, editor. Geomechanics '96. Rotterdam: A. A. Balkema; 1997, p. 235-240. 
[26] Voight B. Beziehung zwischen grossen horizontalen Spannungen im Gebirge und der Tektonik und der Abtragung. In: Proceedings of the First Congress of the International Society of Rock Mechanics, Lisbon, 25 September - 1 October 1966; 1966, p. 51-56.

[27] Martel SJ. Mechanics of curved surfaces, with application to surface-parallel cracks. Geophys. Res. Lett. 2011; 38(L20303):1-6.

[28] Keusen HR, Ganguin J, Schuler P, Buletti M. Grimsel Test Site: Geology. Technical Report 87-14E. Baden: Nagra; 1989.

[29] Ziegler M, Amann F. Internal report about the laboratory test results obtained from core samples from the Grimsel 3 borehole at Kessiturm. ETH Zurich; 2012.

[30] Ulusay R, Hudson JA, editors. The complete ISRM suggested methods for rock characterization, testing, and monitoring: 1974-2006. Ankara: ISRM Turkish National Group; 2007.

[31] Nicksiar M, Martin CD. Evaluation of methods for determining crack initiation in compression tests on low-porosity Rocks. Rock Mech. Rock Eng. 2012; 45(4):607-17.

[32] Diederichs MS. Keynote: stress induced accumulation and implications for hard rock engineering. In: Hammah R, Bawden W, Curran J, Telesnicki M, editors. Proceedings of the 5th North American Rock Mechanics Symposium, Toronto, 7-10 July 2002. Toronto: University of Toronto Press; 2002, p. 3-14.

[33] Martin CD. Seventeenth Canadian Geotechnical Colloquium: The effect of cohesion loss and stress path on brittle rock strength. Can. Geotech. J. 1997; 34:698-725. 
[34] Diederichs MS, Kaiser PK, Eberhardt E. Damage initiation and propagation in hard rock during tunnelling and the influence of near-face stress rotation. Int. J. Rock Mech. Min. Sci. \& Geomech. Abstr. 2004; 41:785-812.

[35] Pan E, Amadei B, Savage WZ. Gravitational stresses in long symmetric ridges and valleys in anisotropic rock. Int. J. Rock Mech. Min. Sci. \& Geomech. Abstr. 1994; 31:293312.

[36] Konietzky H. Versuch excavation disturbed zone 3D stress field and 2D disturbed zone modelling for the Grimsel Test Site. Internal Report 95-62. Wettingen: Nagra; 1995.

[37] Linsbauer A, Paul F, Häberli W. Modeling glacier thickness distribution and bed topography over entire mountain ranges with GlabTop: Application of a fast and robust approach. J. Geophys. Res. 2012; 117(F03007), doi:10.1029/2011JF002313.

[38] Bauder A, Funk M, Gudmundsson GH. The ice-thickness distribution of Unteraargletscher, Switzerland. In: Duval P, Azuma N, Carsey FD, Fisher DA, Fowler AC, Gudmundsson GH et al., editors. Ann. Glaciol.: Papers from the International Symposium on Physical and Mechanical Processes in Ice in relation to Glacier and Ice-Sheet Modelling, held in Chamonix, France, 25-30 August 2002. Cambridge: International Glaciological Society; 2003, p. 331-336.

[39] Stalder HA. Petrographische und mineralogische Untersuchungen im Grimselgebiet (Mittleres Aarmassiv). Schweiz. Mineral. Petrogr. Mitt. 1964; 44:187-398.

[40] Bolay S. Quantitative measurements of exfoliation joint spacing in the Central Aar Granites of the Grimsel area (central Swiss Alps). M.Sc. Thesis. ETH Zurich; 2013. 
[41] Itasca. FLAC3D Version 5.0 - User's guide. Minneapolis, USA: Itasca Consulting Group Inc; 2012.

[42] Tesauro M, Hollenstein C, Egli R, Geiger A, Kahle H. Analysis of central western Europe deformation using GPS and seismic data. J. Geodyn. 2006; 42:194-209.

[43] Nocquet J. Present-day kinematics of the Mediterranean: A comprehensive overview of GPS results. Tectonophysics 2012; 579:220-42.

[44] Müller B, Zoback ML, Fuchs K, Mastin L, Gregersen S, Pavoni N et al. Regional patterns of tectonic stress in Europe. J. Geophys. Res. 1992; 97(B8):11783-803.

[45] Heidbach O, Reinecker J. Analyse des rezenten Spannungsfelds der Nordschweiz. Arbeitsbericht 12-05. Wettingen: Nagra; 2013.

[46] Valley B, Evans KF. Stress orientation to $5 \mathrm{~km}$ depth in the basement below Basel (Switzerland) from borehole failure analysis. Swiss J. Geosci. 2009; 102:467-80.

[47] Burkhard M. Strukturgeologie und Tektonik im Bereich AlpTransit. In: Löw S, Wyss R, editors. Vorerkundung und Prognose der Basistunnels am Gotthard und am Lötschberg: Tagungsband zum Symposium Geologie Alptransit, Zürich, 15-17 February 1999. Rotterdam: A. A. Balkema; 1999, p. 45-56.

[48] Gubler E. Vertical movements in Switzerland. Rock Mech. 1980; 9:193-9.

[49] Sue C, Delacou B, Champagnac J, Allanic C, Tricart P, Burkhard M. Extensional neotectonics around the bend of the Western/Central Alps: an overview. Int. J. Earth Sci. (Geol. Rundschau) 2007; 96:1101-29. 
[50] Maurer HR, Burkhard M, Deichmann N, Green AG. Active tectonism in the central Alps: contrasting stress regimes north and south of the Rhone Valley. Terra Nova 1997; 9(2):91-4.

[51] Delacou B, Sue C, Champagnac J, Burkhard M. Present-day geodynamics in the bend of the western and central Alps as constrained by earthquake analysis. Geophys. J. Int. 2004; 158:753-74.

[52] Kastrup U, Zoback ML, Deichmann N, Evans KF, Giardini D, Michael AJ. Stress field variations in the Swiss Alps and the northern Alpine foreland derived from inversion of fault plane solutions. J. Geophys. Res. 2004; 109(B01402):1-22.

[53] Rummel F, Klee G. Durchführung von Hydraulik- und HydrofracSpannungsmessungen in der Bohrung Handegg-1: Endbericht 07.09. Internal report. Mönchaltorf: Solexperts AG; 2009.

[54] Gruner U, Ziegler H. Pumpspeicherwerk Grimsel 3: Sondierbohrung Kessiturm. Internal report. Bern: Kellerhals \& Haefeli AG; 2011.

[55] Greiner G. Spannungen in der Erdkruste - Bestimmung und Interpretation am Beispiel von in situ-Messungen im süddeutschen Raum. Ph.D Thesis. University Karlsruhe; 1978.

[56] Kirsch G. Theorie der Elastizität und die Bedürfnisse der Festigkeitslehre. Z. VDI $1898 ; 42: 797-807$.

[57] Illies JH, Greiner G. Regionales stress-Feld und Neotektonik in Mitteleuropa. Oberrhein. geol. Abh. 1976; 25:1-40.

[58] Bahat D, Grossenbacher K, Karasaki K. Mechanism of exfoliation joint formation in granitic rocks, Yosemite National Park. J. Struct. Geol. 1999; 21:85-96. 
[59] Brace WF, Paulding BW, Scholz, C. Dilatancy in the fracture of crystalline rocks. J. Geophys. Res. 1966; 71(16):3939-53.

[60] Bieniawski ZT. Mechanism of brittle fracture of rock: Part I - Theory of the fracture process. Int. J. Rock Mech. Min. Sci. \& Geomech. Abstr. 1967; 4(4):395-406.

[61] Diederichs MS, Carvalho JL, Carter TG. A modified approach for prediction of strength and post yield behaviour for high GSI rockmasses in strong, brittle ground. In: Eberhardt E, Stead D, Morrison T, editors. Proceedings of the 1st Canada-US Rock Mechanics Symposium, Vancouver, 27-31 May 2007. London: Taylor \& Francis Group; 2007, p. 249257.

[62] Bucher SP, Loew S. Talklüfte im zentralen Aaregranit der Schöllenen-Schlucht (Kanton Uri, Schweiz). Swiss J. Geosci. 2009; 102(3):403-21.

[63] Leith K, Amann F, Moore JR, Kos A, Löw S. Conceptual modelling of near-surface extensional fracture in the Matter and Saas Valley, Switzerland. In: Williams AL, Massey CI, Chin CY, Pinches GM, McMorran TJ, editors. Geologically active: Proceedings 11th IAEG Congress, Auckland, 5-10 September 2010. London: Taylor \& Francis Group; 2010, p. $363-$ 371.

[64] Lajtai EZ, Schmidtke RH, Bielus LP. The effect of water on the time-dependent deformation and fracture of a granite. Int. J. Rock Mech. Min. Sci. \& Geomech. Abstr. 1987; 24(4):247-55.

[65] Kemeny JM. A model for non-linear rock deformation under compression due to subcritical crack growth. Int. J. Rock Mech. Min. Sci. \& Geomech. Abstr. 1991; 28(6):459-67. 
[66] Backers T, Stephansson O. Time dependent fracture growth in intact crystalline rock: new laboratory procedures. In: Ribeiro e Sousa L, Olalla C, Grossmann N, editors. Proceedings of the 11th Congress of the ISRM, Lisbon, 9-13 July 2007; London: Taylor \& Francis Group; 2007.

[67] Atkinson BK. Subcritical crack growth in geological materials. J. Geophys. Res. 1984; 89(B6):4077-114

[68] Atkinson BK, Meredith PG. The theory of subcritical crack growth with applications to minerals and rocks. In: Atkinson BK, editor. Fracture mechanics of rock. London: Academic Press; 1987, p. 111-166.

[69] Molnar P. Interactions among topographically induced elastic stress, static fatigue, and valley incision. J. Geophys. Res. 2004; 109(F02010):1-9.

[70] Scholz CH. Mechanism of creep in brittle rock. J. Geophys. Res. 1968; 73(10):3295302.

[71] Anderson OL, Grew PC. Stress corrosion theory of crack propagation with applications to geophysics. Rev. Geophys. Space Phys. 1977; 15(1):77-104.

[72] Darot M, Gueguen Y. Slow crack growth in minerals and rocks: Theory and experiments. Pure Appl. Geophys. 1986; 124(4/5):677-92.

[73] Nara Y, Yamanaka H, Oe Y, Kaneko K. Influence of temperature and water on subcritical crack growth parameters and long-term strength for igneous rocks. Geophys. J. Int. 2013.

[74] Damjanac B, Fairhurst C. Evidence for a long-term strength threshold in crystalline rock. Rock Mech. Rock Eng. 2010; 43:513-31. 
[75] Savage WZ, Swolfs HS, Powers PS. Gravitational stresses in long symmetric ridges and valleys. Int. J. Rock Mech. Min. Sci. \& Geomech. Abstr. 1985; 22(5):291-302.

[76] Martel SJ, Muller JR. A two-dimensional boundary element method for calculating elastic gravitational stresses in slopes. Pure Appl. Geophys. 2000; 157:989-1007.

[77] Gruner U, Ziegler H. Geologische Dokumentation Vortrieb Rotlaui - Handeck Loibbach: Neuer Parallelstollen Handeck - Kapf. Internal report. Bern: Kellerhals \& Haefeli AG; 2009.

[78] Cadisch J. Die Geologie im Dienste des alpinen Kraftwerkbaues. Tech. Rundschau $1944 ; 31: 1-8$.

[79] Rogers CM, Engelder T. The feedback between joint-zone development and downward erosion of regularly spaced canyons in the Navajo Sandstone, Zion National Park, Utah. In: Cosgrove JW, Engelder T, editors. The initiation, propagation, and arrest of joints and other fractures; 2004, p. 49-71.

[80] Amadei B, Pan E. Role of topography and anisotropy when selecting unlined pressuretunnel alignment. J. Geotech. Eng. 1995; 121:879-85.

[81] Zoback ML. First- and second-order patterns of stress in the lithosphere: The world stress map project. J. Geophys. Res. 1992; 97(B8):11703-28.

[82] Greiner G, Illies JH. Central Europe: Active or residual tectonic stresses. In: Wyss M, editor. Stress in the earth: reprint from Pure Appl. Geophys. 115(1-2). Basel, Stuttgart: Birkhäuser; 1977, p. 11-26.

[83] Park RG. Geological structures and moving plates. Glasgow (UK): Blackie and Sons; 1988. 
[84] Pascal C, Roberts D, Gabrielsen RH. Tectonic significance of present-day stress relief phenomena in formerly glaciated regions. J. Geol. Soc. 2010; 167:363-71.

[85] Stephansson O, Ljunggren C, Jing L. Stress measurements and tectonic implications for Fennoscandia. Tectonophysics 1991; 189:317-22.

[86] Kieslinger A. Spannungen und Entspannungen im Steinbruchbetrieb. Berg- und Hüttenmännische Monatshefte 1968; 113(8):298-304.

[87] Nichols TC Jr. Rebound, its nature and effect on engineering works. Q. J. Eng. Geol. London 1980; 13:133-52.

[88] Nadan BJ, Engelder T. Microcracks in New England granitoids: A record of thermoelastic relaxation during exhumation of intracontinental crust. Geol. Soc. Am. Bull. 2009; 121(1/2):80-99.

[89] Gruner U, Ziegler H. KWO plus Erschliessungsstollen Handeck - Gerstenegg: Aufnahme von Sondierbohrungen im Bereich Handeck / Widmannshöhe. Internal report. Bern: Kellerhals \& Haefeli AG; 2009.

[90] Pfiffner OA, Deichmann N. Arbeitsbericht 14-26: Seismotektonik der Zentralschweiz. Wettingen: Nagra; 2014.

[91] Harrison JC. Cavity and topographic effects in tilt and strain measurement. J. Geophys. Res. 1976; 81(2):319-28.

[92] Augustinus P. Glacial valley cross-profile development: the influence of in situ rock stress \& rock mass strength, with examples from the Southern Alps, New Zealand. Geomorphology $1995 ; 14: 87-97$. 
[93] Bell JS, Gough DI. Northeast-southwest compressive stress in Alberta: Evidence from oil wells. Earth Planet. Sci. Lett. 1979; 45:475-82.

[94] Lee M, Haimson B. Laboratory study of borehole breakouts in Lac du Bonnet Granite: a case of extensile failure mechanism. Int. J. Rock Mech. Min. Sci. \& Geomech. Abstr. 1993; 30(7):1039-45.

[95] Martin CD, Kaiser PK, McCreath DR. Hoek-Brown parameters for predicting the depth of brittle failure around tunnels. Can. Geotech. J. 1999; 36:136-51.

[96] Read RS. 20 years of excavation response studies at AECL's underground research laboratory. Int. J. Rock Mech. Min. Sci. \& Geomech. Abstr. 2004; 41:1251-75.

[97] Rolland Y, Cox SF, Corsini M. Constraining deformation stages in brittle-ductile shear zones from combined field mapping and 40Ar/39Ar dating: The structural evolution of the Grimsel Pass area (Aar Massif, Swiss Alps). J. Struct. Geol. 2009; 31:1377-94.

[98] Abrecht J. Geologic units of the Aar massif and their pre-Alpine rock associations: a critical review: Kleinere Mitteilungen Nr. 95. Präalpine Entwicklung des Aar- und Gotthardmassivs. Schweiz. Mineral. Petrogr. Mitt. 1994; 74(1):5-27.

[99] Choukroune P, Gapais D. Strain pattern in the Aar Granite (Central Alps): orthogneiss developed by bulk inhomogeneous flattening. J. Struct. Geol. 1983; 5(3/4):411-8.

[100] Obara Y, Chang HK, Sugawara K, Sakaguchi K. Measurement of stress distribution around fault and considerations. In: Rossmanith $\mathrm{H}$, editor. Mechanics of jointed and faulted rock: Proceedings of the 2nd international conference on the mechanics of jointed and faulted rock - MJFR-2. Rotterdam: A. A. Balkema; 1995, p. 495-500. 


\section{Appendix A}

Initial gravitational stress conditions based on the assumption of a linear-elastic material

For a uniform layer of rock, i.e., where stresses are not influenced by topography, the vertical stress component, $S_{v}$, is calculated by using Eq. A.1:

$S_{v}=\rho_{r m} g z$

with rock mass density, $\rho_{r m}$, gravitational acceleration, $g$, and depth below surface, $z$. The horizontal stress components, $S_{H, g r a v}$ and $S_{h, g r a v}$, due to gravity in a laterally confined rock mass are given by Eq. A.2:

$S_{H, \text { grav }}=S_{h, \text { grav }}=\frac{v_{r m}}{1-v_{r m}} \cdot S_{v}=k \cdot S_{v}$

with a rock mass Poisson's ratio, $v_{r m}[41]$. This stress state is referred elsewhere to as the 'perfect lateral constraint' state (e.g., Liu and Zoback [17] and references therein).

\section{Simulating high, near-surface subhorizontal stresses}

For a rock mass with uniform thickness overall horizontal stresses are given by superposition of the gravitational and far-field (tectonic and/or remnant) stress components according to Eq. A.3:

$S_{H}=k_{S H / S h} \cdot S_{h}=S_{H, \text { grav }}+S_{H, \text { far-field }}$

The inverse version of Hooke's Law can be written as Eqs. A.4 to A.6 (the superscript el stands for elastic):

$$
\begin{aligned}
& \varepsilon_{x x}^{e l}=\frac{1}{E}\left[\sigma_{x x}-v\left(\sigma_{y y}+\sigma_{z z}\right)\right] \\
& \varepsilon_{y y}^{e l}=\frac{1}{E}\left[\sigma_{y y}-v\left(\sigma_{x x}+\sigma_{z z}\right)\right] \\
& \varepsilon_{z z}^{e l}=\frac{1}{E}\left[\sigma_{z z}-v\left(\sigma_{x x}+\sigma_{y y}\right)\right]
\end{aligned}
$$


Solving Eq. A.5 for $\sigma_{y y}$ and utilizing the expression for $\sigma_{y y}$ in Eq. A.4 we can solve for $\sigma_{x x}$ (Eq. A.7), and for $\sigma_{y y}$ (Eq. A.8). Setting $\sigma_{z z}$ equal to $S_{v}$ we obtain:

$$
\begin{aligned}
& \sigma_{x x}=\frac{v \cdot S_{v}(1+v)+E \cdot\left(\varepsilon_{x x}^{e l}+v \cdot \varepsilon_{y y}{ }^{e l}\right)}{1-v^{2}}=\frac{v \cdot S_{v}}{1-v}+\frac{E \cdot\left(\varepsilon_{x x}^{e l}+v \cdot \varepsilon_{y y}{ }^{e l}\right)}{1-v^{2}} \\
& \sigma_{y y}=\frac{v \cdot S_{v}(1+v)+E \cdot\left(\varepsilon_{y y} e l+v \cdot \varepsilon_{x x}{ }^{e l}\right)}{1-v^{2}}=\frac{v \cdot S_{v}}{1-v}+\frac{E \cdot\left(\varepsilon_{y y}{ }^{e l}+v \cdot \varepsilon_{x x} e l\right)}{1-v^{2}}
\end{aligned}
$$

The first term on the right side of Eq. A.7 and Eq. A.8 is equal to $S_{H / h, \text { grav }}$, while the second term equals $S_{H / h, \text { far-field }}$ In case of anisotropic horizontal stresses (strains) we can calculate the additional far-field stress components, $S_{H, f a r-f i e l d}$ and $S_{h, \text { far-field }}$ (Eq. A.9 and Eq. A.10). These components honor plane stress requirements.

Setting $v=v_{r m}, E=E_{r m}, \sigma_{x x}=S_{H}$, and $\sigma_{y y}=S_{h}\left(\right.$ for $\left.\sigma_{x x}>\sigma_{y y}\right)$, we obtain:

$$
\begin{aligned}
S_{H, f a r-f i e l d} & =\frac{E_{r m}\left(\varepsilon_{x x}^{e l}+v_{r m} \varepsilon_{y y}{ }^{e l}\right)}{1-v_{r m}{ }^{2}} \\
S_{h, \text { far-field }} & =\frac{E_{r m}\left(\varepsilon_{y y}{ }^{e l}+v_{r m} \varepsilon_{x x}{ }^{e l}\right)}{1-v_{r m}{ }^{2}}
\end{aligned}
$$

Setting $\varepsilon_{x x}{ }^{e l}$ equal to $\varepsilon_{y y}{ }^{e l}$ for isotropic strain we obtain Eq. A.11:

$$
S_{H, f a r-f i e l d}=S_{h, f a r-f i e l d}=\frac{E_{r m} \cdot \varepsilon_{x x} e l}{\left(1-v_{r m}\right)}=\frac{E_{r m} \cdot \varepsilon_{y y}^{e l}}{\left(1-v_{r m}\right)}
$$

\section{Figure Captions}

Fig. 1. Example of a radial plumose structure on a steep exfoliation joint northeast of Lake Räterichsboden [21] (for location see Fig. 3). Dotted arrows mark the plumose axis and major fracture propagation directions. The plumose axes is assumed to form parallel to the maximum compressive principal stress $\left(\sigma_{1}\right)$ at the time of fracture propagation. The pitch (or rake) angle of the plumose axis is the angle between the plume axis and a horizontal line (strike line) as measured in the plane of the joint. It can range from $0^{\circ}$ (horizontal plume axis) to $90^{\circ}$ 
(plume axis plunges parallel to the dip direction of the common joint plane), and in this example equals about $50^{\circ}$.

Fig. 2. ' $0^{\circ}$-model' discretisation. The mesh density increases with decreasing distance to the landscape surface. The difference between the current topography (green) and palaeo topography (blue) is indicated and in situ stress measurement sites are shown (yellow). For interpretation of the reference to colour in this figure, the reader is referred to the web version of the article.

Fig. 3. Locations of the $0^{\circ}$ - and $45^{\circ}$-model vertical boundaries and 'observation points' for near-surface stress investigation in the Grimsel area (background: modified digital elevation model DHM25, swisstopo). The models enclose most of the area of a previous model by Konietzky [36]. The occurrences of exfoliation fractures that are visible at the landscape surface are shown in brown colour [6]. Main and hanging trough valley floors are widely covered by debris. Hanging trough valleys are located west and east of Handegg (i.e., Ärlen and Gelmer valley) and west of Lake Räterichsboden (i.e., Bächli valley).

Fig. 4. Map of near-surface (the term 'near-surface' is defined in Section 2.2) $\sigma_{3}$ magnitudes (colour coded) and principal stress trajectories $\left(0^{\circ}\right.$-model with palaeo topography; gravitational stresses; tensile stresses are negative; background: modified DHM25, swisstopo). Areas of high elevation and the subsurface are for the most part under compressive stresses in all directions. Greatest concentrations of tensile stresses exist along parts of the valley bottom of the main, NNW-SSE directed upper Hasli valley up to Grimsel Pass. There the trend of the minimum principal stress is about perpendicular to the valley axis (the orientation of $\sigma_{3}$ is indicated in blue). 
Fig. 5. Map showing the trends of modelled near-surface principal stresses $\left(\sigma_{1}\right.$ and $\sigma_{2} ; \sigma_{3}<<$ $\sigma_{2}$ ) derived after about 0.22 mstrain ( $3 \mathrm{~m}$ horizontal displacement), $0.37 \mathrm{mstrain}$ ( $5 \mathrm{~m}$ horizontal displacement) and 0.52 mstrain $(7 \mathrm{~m}$ horizontal displacement $)\left(0^{\circ}\right.$-model; gravitational stresses and additional isotropic far-field stresses; palaeo topography; background: modified DHM25, swisstopo). Principal stress magnitudes were scaled for better reading (scaling: 1.94:1.36:1 for 0.22:0.37:0.52 mstrain). Principal stresses located below trough valley floors show little $\left(<5^{\circ}\right)$ rotation of $\sigma_{1}$ for the selected range of strain magnitudes. In contrast, the slopes close to and above valley shoulders show rotations greater than $5^{\circ}$ for $\sigma_{l}$ (see, e.g., the valley section west of Grimsel Pass). Highest compressive stresses occur within inner main and hanging trough valleys. This is due to the 'notch effect' of valleys, i.e. stresses are concentrated in the vicinity of depressions subjected to compressive lateral stress (see also Fig. 6).

Fig. 6. Map of near-surface $\sigma_{1}$ magnitudes and principal stress trends $\left(0^{\circ}\right.$-model with palaeo topography; gravitational stress model subjected to isotropic horizontal strains of 0.37 mstrain; background: modified DHM25, swisstopo). Maximum compressive stresses occur in inner trough valleys and range mostly between $40 \mathrm{MPa}$ and $80 \mathrm{MPa}$. Upper slopes and crests show reduced compressive stresses, mostly $<40 \mathrm{MPa}$. The orientations of $\sigma_{1}$ are strongly influenced by topography showing substantial rotations close to the landscape surface. For instance, $\sigma_{l}$ orientations trend about NNW-SSE to N-S in the valley section west of Grimsel Pass and about W-E to WSW-ENE in the valley section north of Grimsel Pass.

Fig. 7. $\sigma_{1} / \sigma_{3}(\mathrm{~A}-\mathrm{D}$ and $\mathrm{I}-\mathrm{L})$ and $\sigma_{1} / \sigma_{2}$ ratios $(\mathrm{E}-\mathrm{H}$ and $\mathrm{M}-\mathrm{P})$ for different depth $(15 \mathrm{~m}, 30 \mathrm{~m}$, $45 \mathrm{~m}$, and $60 \mathrm{~m}$ ) below the palaeo-topography in the isotropic strain model with 0.37 mstrain 
$\left(0^{\circ}\right.$-model; A-H) and the anisotropic strain model with 0.45 mstrain in NW-direction and 0.11 mstrain in SW-direction $\left(45^{\circ}\right.$-model; I-P).

Fig. 8. Spherical projection showing modelled principal and maximum horizontal stress rotation at four observation points $(\mathrm{A}-\mathrm{D})\left(0^{\circ}\right.$-model with current topography). The gravitational stress model (no displacement of vertical boundaries) was subjected to horizontal strains as large as $\sim 0.74$ mstrain ( $\cong 10 \mathrm{~m}$ displacement along y-axis). Ranges and mean results of in situ $S_{H}$ trends are marked by grey sectors and grey tick marks at the periphery of the plots (cf., Table 3) and can be compared with $S_{H}$ trends (arrows) calculated from modelled stress tensors.

Fig. 9. Change of principal, horizontal, and vertical stress magnitudes and stress ratios at four observation points due to increasing horizontal strains $\left(0^{\circ}\right.$-model with current topography). A-D. The gravitational stress model was subjected to isotropic horizontal strain as large as 0.74 mstrain. Horizontal and vertical stress components were calculated for strain increments of 0.037 mstrain. E-H. The gravitational stress model was subjected to anisotropic horizontal strains as large as 0.90 mstrain in W-E direction and as large as 0.21 mstrain in N-S direction. Horizontal and vertical stress components were calculated for strain increments of 0.045 mstrain (W-E) and 0.011 mstrain $(\mathrm{N}-\mathrm{S})$. For comparison, the in situ stress magnitudes are

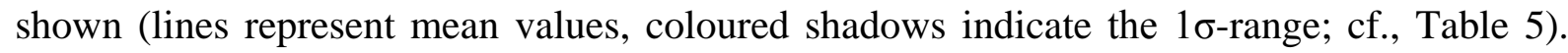
Modelled values of $\sigma_{3}$ are shown by a solid line that passes near, but not precisely through, the centres of the green circles representing modelled $S_{v}$.

Fig. 10. Spherical projection showing modelled principal and maximum horizontal stress rotation at four observation points $(\mathrm{A}-\mathrm{D})\left(0^{\circ}\right.$-model with current topography). The gravitational 
model was subjected to horizontal strains up to 0.90 mstrain in W-E direction and 0.21 mstrain in $\mathrm{N}-\mathrm{S}$ direction (strain magnitudes shown are given for the W-E direction). Ranges and mean results of in situ $S_{H}$ trends are marked by grey sectors and grey tick marks at the periphery of the plots (cf., Table 3) and can be compared with $S_{H}$ trends (arrows) calculated from modelled stress tensors.

Fig. 11. Comparison between $\sigma_{l}$ trends inferred from plumose structure axes and modelled $\sigma_{l}$ trends around Lake Räterichsboden (gravitational stress model subjected to (A) isotropic regional horizontal strains of 0.37 mstrain and (B) anisotropic regional horizontal strains of 0.45 mstrain in $\mathrm{W}$-E direction and 0.11 mstrain $\mathrm{N}-\mathrm{S}$ direction; $0^{\circ}$-model with palaeo topography; background: digital elevation model DTM-AV, swisstopo).

Fig. 12. Comparison between $\sigma_{l}$ trends inferred from plumose structure axes and modelled $\sigma_{l}$ trends north of Lake Räterichsboden (Detail A; Fig. 11). The numerical model details of A and B are given in the caption of Fig. 11.

Fig. 13. Histograms with $15^{\circ}$ bin widths of the angular differences between measured plume axes and modelled $\sigma_{l}$ orientations located north of Lake Räterichsboden (A), at detail A north of Lake Räterichsboden (B), and south of Lake Grimsel (C). A, B, and C correspond to Fig. 11, Fig. 12, and Fig. 14. Black bars represent results from the 0.37 mstrain isotropic $0^{\circ}$-model, grey bars refer to the anisotropic $0^{\circ}$-model with W-E directed maximum contractional strain of 0.45 mstrain. 
Fig. 14. Comparison between $\sigma_{l}$ trends inferred from plumose structure axes and modelled $\sigma_{1}$ trends south of Lake Grimsel. The numerical model details of A and B are given in the caption of Fig. 11.

Fig. 15. Decrease of $k$-values with depth below ground for isotropic ( 0.37 mstrain; solid black line) and anisotropic models (0.45 mstrain and 0.11 mstrain for different directions according to $k_{S H / S h}$, far-field $=2$; solid black line and dotted grey line). Individual borehole in situ stress measurement results from four sites located within the research (and modelled) area are given. We calculated $S_{v}$ using the load of the overburden, omitting topographic effects. These data can be compared with our anisotropic $\left(k_{S H / S h, \text { far-field }}=2\right)$ model results at different strains.

\section{Tables}

Table 1. Material properties of intact Central Aar Granite [28] (CAGr) and corresponding rock mass. We used CAGr data as input for isotropic elastic modelling. For comparison we list material properties for intact Grimsel Granodiorite [29] (GrGr).

Table 2. Model discretisation.

Table 3. Magnitude and orientation of in situ stresses inferred from borehole-based stress measurements $\left(S_{v}\right.$ : vertical stress; $S_{h}$ : minimum horizontal stress; $S_{H}$ : maximum horizontal stress).

Table 4. Observation point parameters. 
Table 5. Comparison of in situ stresses inferred from measurements in boreholes with stresses at observation points from 'gravitational stress models' (current and palaeo ground surface; all stresses are given in MPa). The vertical, minimum horizontal, and maximum horizontal stresses are denoted $S_{v}, S_{h}$, and $S_{H}$, and the maximum, intermediate, and minimum principal stresses are denoted $\sigma_{1}, \sigma_{2}$, and $\sigma_{3}$. The octahedral mean stress is given by $\sigma_{m}=\left(\sigma_{1}+\sigma_{2}+\sigma_{3}\right) / 3$.

Table 6. $k_{S H / S h}{ }^{-v a l u e s}$ at observation points for the selected models with current topography. (+) and (-) indicate 'improvement' and 'worsening' of $k_{S H / S h}$ with respect to isotropic strain models. ${ }^{[*]}$ marks the model with best fit with respect to $k_{S H / S h}$, and ${ }^{[* *]}$ with best fit with respect to $S_{H}$ orientation.

\section{Appendix B (electronic supplementary material - Figure Captions)}

Fig. B.1. ' $45^{\circ}$-model' discretisation. The mesh density increases with decreasing distance to the landscape surface. The difference between the current topography (green) and palaeo topography (blue) is indicated and in situ stress measurement sites are shown (yellow).

Fig. B.2. Map of near-surface (the term 'near-surface' is defined in Section 2.2) $\sigma_{3}$ magnitudes (colour coded) and principal stress trajectories $\left(45^{\circ}\right.$-model with palaeo topography; gravitational stresses; tensile stresses are negative; background: modified DHM25, swisstopo). Areas of high elevation and the subsurface are for the most part under compressive stresses. Greatest concentrations of tensile stresses exist along parts of the valley bottom of the main, NNWSSE directed upper Hasli valley up to Grimsel Pass. There the trend of $\sigma_{3}$ is about perpendicular to the valley axis (the orientation of $\sigma_{3}$ is indicated in blue). 
Fig. B.3. Map of near-surface $\sigma_{1}$ magnitudes and principal stress trends ( $45^{\circ}$-model with palaeo topography; gravitational stress model subjected to isotropic horizontal strains of 0.37 mstrain; background: modified DHM25, swisstopo).

Fig. B.4. Map of near-surface $\sigma_{1}$ magnitudes and principal stress trends derived from anisotropic $\left(\varepsilon_{W-E}=4.25 \cdot \varepsilon_{N-S}\right.$ for $S_{H, \text { far-field }}=2 \cdot S_{h, \text { far-field }}$, with $S_{H, \text { far-field }}$ along X-axis) strain models $\left(0^{\circ}\right.$ model with palaeo topography; gravitational stresses and additional anisotropic horizontal farfield stresses; background: modified DHM25, swisstopo).

Fig. B.5. Map of near-surface $\sigma_{l}$ magnitudes and principal stress trends derived from anisotropic $\left(\varepsilon_{N W-S E}=4.25 \cdot \varepsilon_{S W-N E}\right.$ for $S_{H, f a r-f i e l d}=2 \cdot S_{h, f a r-f i e l d}$, with $S_{H, f a r-f i e l d}$ along y'-axis $)$ strain models (45 ${ }^{\circ}$-model with palaeo topography; gravitational stresses and additional anisotropic horizontal far-field stresses; background: modified DHM25, swisstopo).

Fig. B.6. Map of near-surface $\sigma_{l}$ magnitudes and principal stress trends derived from anisotropic $\left(\varepsilon_{N-S}=4.25 \cdot \varepsilon_{W-E}\right.$ for $S_{H, f a r-f i e l d}=2 \cdot S_{h, f a r-f i e l d}$, with $S_{H, f a r-f i e l d}$ along y-axis) strain model $\left(0^{\circ}-\right.$ model with palaeo topography; gravitational stresses and additional anisotropic horizontal farfield stresses; background: modified DHM25, swisstopo).

Fig. B.7. Map of near-surface $\sigma_{l}$ magnitudes and principal stress trends derived from anisotropic $\left(\varepsilon_{S W-N E}=4.25 \cdot \varepsilon_{N W-S E}\right.$ for $S_{H, f a r-f i e l d}=2 \cdot S_{h, f a r-f i e l d}$, with $S_{H, f a r-f i e l d}$ along X'-axis) strain models (45 ${ }^{\circ}$-model with palaeo topography; gravitational stresses and additional anisotropic horizontal far-field stresses; background: modified DHM25, swisstopo). 
Table 1

\begin{tabular}{lllll}
\hline Parameter & & Unit & Value $(\mathrm{CAGr})$ & \left.${\text { Value }(\mathrm{GrGr})^{\mathrm{a}}}^{\mathrm{a}}\right)$ \\
\hline \multirow{4}{*}{$\begin{array}{l}\text { Intact rock } \\
\text { (i) }\end{array}$} & Density, $\rho_{i}$ & {$\left[\mathrm{~kg} / \mathrm{m}^{3}\right]$} & $2660 \pm 23.8\left(1 \sigma^{\mathrm{b}}\right)$ & $2726-2743$ \\
& Unconfined Compressive Strength, $U C S_{i}$ & {$[\mathrm{MPa}]$} & $169 \pm 37.1(1 \sigma)$ & $133-185$ \\
& Young 's modulus, $E_{i}$ & {$[\mathrm{GPa}]$} & $53.3 \pm 11.0(1 \sigma)$ & $50-64\left(E_{50, \text { tangent }}\right)$ \\
& Poisson's ratio, $v_{i}$ & {$[-]$} & $0.37 \pm 0.12(1 \sigma)$ & $0.17-0.41$ \\
& Crack initiation stress level, $c_{i}$ & {$[\mathrm{MPa}]$} & - & $52-93$ \\
\hline \multirow{5}{*}{ Rock mass } \\
(rm) & Density, $\rho_{r m}$ & {$\left[\mathrm{~kg} / \mathrm{m}^{3}\right]$} & 2660 & - \\
& Poisson's ratio, $v_{r m}$ & {$[-]$} & 0.3 & - \\
& Young 's modulus, $E_{r m}$ & {$[\mathrm{GPa}]$} & 47 & - \\
& Bulk modulus, $K_{r m}$ & {$[\mathrm{GPa}]$} & 39 & - \\
& Shear modulus, $G_{r m}$ & {$[\mathrm{GPa}]$} & 18 & - \\
\hline
\end{tabular}

${ }^{a}$ based on 8 macroscopically unweathered, coarse granodioritic augengneiss samples taken from the Kessiturm borehole at depths between about $90 \mathrm{~m}$ and $530 \mathrm{~m}$ (for bore hole location see Fig. 3). The unconfined compressive strength (UCS) tests were performed utilising a modified $2000 \mathrm{kN}$ Walter \& Bai servo-hydraulic rock testing device with digital feedback control according to the ISRM suggested methods [30]. Crack initiation thresholds were determined according to Nicksiar and Martin [31] and using circumferential strain response.

${ }^{\mathrm{b}} 1 \sigma$ range of the standard deviation. 
Table 2

Elevation [m asl.]

Edge length of cubic elements [m]

below today's topography (62.5 m extent)

15.625

below today's topography ( $250 \mathrm{~m}$ extent)

31.25

0 to $250 \mathrm{~m}$ below topography

62.5

-2000 to 0

125

-5000 to -2000

250

-10000 to -5000

500


Table 3

\begin{tabular}{|c|c|c|c|c|c|c|c|c|}
\hline Location & $\begin{array}{l}\text { Meas- } \\
\text { urement } \\
\text { method }\end{array}$ & $\begin{array}{l}\text { Overburden } \\
\text { (main rock type) }\end{array}$ & $S_{v}$ & $\overline{S_{h}}$ & $S_{H}$ & $k_{S H / S v}$ & Orientation of $S_{H}$ & Reference \\
\hline & & {$[\mathrm{m}]$} & [MPa] & [MPa] & [MPa] & {$[-]$} & {$\left[{ }^{\circ}\right]$} & \\
\hline Handegg-1 & $\mathrm{HF}$ & 40-77 (CAGr) & $1.1-2.0$ & $7.4-9.0^{\mathrm{a}}$ & $14.2-17.3^{b}$ & $4.8-14.0$ & W-E $(\mathrm{N} 86 \mathrm{E} \pm 40)$ & [53] \\
\hline $\begin{array}{l}\text { NAGRA GTS }^{c} \\
\text { (GS 84.041 A) }\end{array}$ & $\mathrm{OC}$ & 490-680 (CAGr) & $11-14$ & $15-30$ & $25-40$ & $1.1-3.7$ & $\begin{array}{l}\text { WNW-ESE and } \\
\text { NNW-SSE }\end{array}$ & [24] \\
\hline Kessiturm & $\mathrm{HF}$ & $320-570(\mathrm{GrGr})$ & $8.7-15.5$ & $7.8-22.3^{\mathrm{a}}$ & $9.5-37.3^{\mathrm{b}}$ & $1.1-2.4$ & $\begin{array}{l}\text { W-E }(\mathrm{N} 90 \mathrm{E} \pm 33)^{\mathrm{d}} \\
\mathrm{W}-\mathrm{E} \text { to } \mathrm{NW}-\mathrm{SE}^{\mathrm{e}}\end{array}$ & {$[54]^{\mathrm{f}}$} \\
\hline Grimsel-2 ${ }^{\mathrm{g}}$ & $\mathrm{OC}$ & 265 (GrGr) & $7.0^{\mathrm{h}}$ & $15.1 \pm 0.8$ & $17.4 \pm 0.9$ & 2.5 & $\mathrm{~N}-\mathrm{S}(\mathrm{N} 171 \mathrm{E} \pm 11)$ & {$[55]$} \\
\hline
\end{tabular}

a From breakdown pressure.

${ }^{\mathrm{b}}$ From reopening pressure.

${ }^{\mathrm{c}}$ A constant E-modulus of $40 \mathrm{GPa}$ and a Poisson ratio of 0.25 were used to calculate horizontal stress components assuming isotropic rock mass behaviour (cf., Table 1)

${ }^{\mathrm{d}}$ Calculated using the four most reliable hydraulic fracture orientations at depth of $370 \mathrm{~m}, 420 \mathrm{~m}, 470 \mathrm{~m}$, and $569 \mathrm{~m}$.

${ }^{\mathrm{e}}$ Borehole breakouts between $568 \mathrm{~m}$ and $590 \mathrm{~m}$ suggest W-E to NW-SE direction of $S_{H}$.

${ }^{\mathrm{f}}$ Report by Stump Foratec SA / Polymetra from December 20th, 2011 (presented as Appendix 6 in [54])

${ }^{\mathrm{g}}$ A constant E-modulus of about $19.2 \mathrm{GPa}$ and a Poisson ratio of 0.2 were used to calculate horizontal stress components (cf., Table 1). The assumption of a low E-modulus may have led to considerable underestimation of $S_{H}$ and $S_{h}$. In addition, the assumption of isotropic E-modulus for granodioritic gneiss, although based on in situ measurements, is questionable.

${ }^{\mathrm{h}}$ With $\rho=2.70$ [28]; calculated from overburden weight, not including topographic effects.

HF: Hydraulic Fracturing.

OC: Overcoring. 
Table 4

\begin{tabular}{|c|c|c|c|c|c|}
\hline \multirow[t]{2}{*}{ Location } & \multicolumn{3}{|c|}{ Coordinates (CH1903+; element centre) } & \multirow{2}{*}{$\begin{array}{l}\text { Number of elements } \\
\text { (edge length in }[\mathrm{m}] \text { ) }\end{array}$} & \multirow{2}{*}{$\begin{array}{l}\text { 'Overburden' [m] } \\
\text { (after erosion) }\end{array}$} \\
\hline & $\mathrm{x}$ & $\mathrm{y}$ & $\mathrm{z}$ [m asl.] & & \\
\hline I: Handegg-1 & 2666310 & 1162660 & 1385 & $1(15.625)$ & $100(55)$ \\
\hline II: GTS (Section 1) & 2667445 & 1159200 & 1720 & $1(62.5)$ & $515(480)$ \\
\hline III: Kessiturm & 2667165 & 1157435 & 1765 & $1(62.5)$ & $470(440)$ \\
\hline IV: Grimsel-2a & 2667300 & 1157770 & 1765 & $1(31.25)$ & $280(240)$ \\
\hline
\end{tabular}

${ }^{a}$ The location coordinates are not precisely known. Model coordinates roughly fulfil the location description given in Illies and Greiner [57].

${ }^{\mathrm{b}}$ Approximated. 
Table 5

\begin{tabular}{|c|c|c|c|c|c|c|c|c|c|c|c|c|c|c|c|c|c|c|}
\hline \multirow[b]{2}{*}{ Location } & \multicolumn{3}{|c|}{ In situ stress ${ }^{\mathrm{a}}$} & \multirow{2}{*}{$\begin{array}{l}\text { Model topography } \\
\text { c: current; p: palaeo }\end{array}$} & \multicolumn{8}{|c|}{$0^{\circ}$-model } & \multicolumn{6}{|c|}{$45^{\circ}$-model } \\
\hline & $S_{H}$ & $S_{h}$ & $S_{v}$ & & $\sigma_{l}$ & $\sigma_{2}$ & $\sigma_{3}$ & $\sigma_{m}$ & $S_{H}$ & $S_{h}$ & $S_{v}$ & $\sigma_{l}$ & $\sigma_{2}$ & $\sigma_{3}$ & $\sigma_{m}$ & $S_{H}$ & $S_{h}$ & $S_{v}$ \\
\hline I: Handegg-1 & 15.0 & 8.4 & 1.6 & $\mathrm{c}$ & 3.7 & 2.7 & 1.0 & 2.5 & 2.8 & 1.3 & 1.4 & 4.3 & 2.1 & 0.3 & 2.2 & 3.0 & 0.3 & 0.7 \\
\hline (1380 m asl.) & \pm 3.0 & \pm 1.2 & & $\mathrm{p}$ & 5.9 & 3.8 & 2.0 & 3.9 & 3.8 & 2.5 & 2.9 & 6.2 & 3.4 & 1.4 & 3.7 & 3.9 & 1.6 & 2.5 \\
\hline II: GTS & 31.2 & 22.4 & 10.5 & $\mathrm{c}$ & 11.8 & 4.9 & 2.9 & 6.5 & 4.9 & 3.0 & 8.9 & 11.8 & 4.8 & 3.0 & 6.5 & 4.8 & 3.1 & 8.9 \\
\hline (1720 m asl.) & \pm 7.5 & \pm 5.1 & & $\mathrm{p}$ & 12.6 & 5.2 & 3.3 & 7.0 & 5.2 & 3.3 & 9.7 & 12.6 & 5.1 & 3.4 & 7.0 & 5.1 & 3.5 & 9.8 \\
\hline III: Kessiturm & 26.8 & 14.5 & 11.4 & $\mathrm{c}$ & 12.7 & 4.8 & 3.9 & 7.1 & 5.2 & 3.9 & 8.9 & 13.1 & 4.9 & 4.0 & 7.3 & 5.3 & 4.0 & 8.9 \\
\hline (1780 m asl.) & \pm 4.7 & \pm 4.5 & & $\mathrm{p}$ & 13.4 & 5.3 & 4.3 & 7.7 & 5.7 & 4.3 & 9.9 & 13.8 & 5.3 & 4.4 & 7.8 & 5.7 & 4.4 & 9.9 \\
\hline IV: Grimsel-2 & 17.4 & 15.1 & 7.0 & $\mathrm{c}$ & 9.8 & 4.3 & 2.6 & 5.6 & 4.9 & 2.6 & 5.9 & 10.4 & 4.2 & 2.8 & 5.8 & 5.0 & 2.8 & 6.2 \\
\hline (1765 m asl.) & & & & $\mathrm{p}$ & 10.5 & 5.0 & 3.0 & 6.2 & 5.5 & 3.0 & 7.0 & 10.9 & 4.8 & 3.2 & 6.3 & 5.6 & 3.2 & 7.2 \\
\hline GTS:L230' & - & - & - & $\mathrm{c}$ & - & - & - & & - & - & - & 11.2 & 4.7 & 3.8 & 6.6 & - & - & - \\
\hline
\end{tabular}

a Stress magnitude mean value and one standard deviation range derived from borehole intervals close to model observation points. The data is based on: Handegg-1: 8 hydraulic fracturing (HF) measurements between $40 \mathrm{~m}$ and $77 \mathrm{~m}$ bgs.; Grimsel Test Site: 9 overcoring (OC) measurements between $\sim 490 \mathrm{~m}$ and $\sim 530 \mathrm{~m}$ bgs. (Section 1); Kessiturm: $3 \mathrm{HF}$ measurements between $370 \mathrm{~m}$ and $470 \mathrm{~m}$ bgs.; Grimsel-2: 7 OC measurements ('doorstopper'-method) within an interval of $3.1 \mathrm{~m}$ (cf., Table 3).

b For comparison we give stress results at point L230 from the three-dimensional elastic model by Konietzky [36]. Point L230 is located at 2667453/1159145/1729 (x/y/z in m) and about $56 \mathrm{~m}$ away from location GTS (cf., Table 3). Stress magnitudes for model comparison are marked bold. 
Table 6

\begin{tabular}{|c|c|c|c|c|c|c|c|}
\hline $\begin{array}{l}\text { Model } \\
\text { Orientation of maximum } \\
\text { far-field stress }\end{array}$ & $\begin{array}{l}0^{\circ} \text {-model } \\
\text { (isotropic) }\end{array}$ & $\begin{array}{l}0^{\circ} \text {-model } \\
S_{H, y}(\mathrm{~N}-\mathrm{S})\end{array}$ & $\begin{array}{l}0^{\circ} \text {-model } \\
S_{H, x}(\mathrm{~W}-\mathrm{E})\end{array}$ & $\begin{array}{l}45^{\circ} \text {-model } \\
\text { (isotropic) }\end{array}$ & $\begin{array}{l}45^{\circ} \text {-model } \\
S_{H, y^{\prime}}(\mathrm{NW}-\mathrm{SE})\end{array}$ & $\begin{array}{l}45^{\circ} \text {-model } \\
S_{H, x^{\prime}}(\mathrm{SW}-\mathrm{NE})\end{array}$ & $\begin{array}{l}\text { In situ horizon- } \\
\text { tal stress ratio, } \\
k_{S H / S h}\end{array}$ \\
\hline I: Handegg-1 & $1.80^{*}$ & $2.26(-)$ & $1.47(-)^{* * *}$ & 2.13 & $2.63(-)$ & $1.47(-)$ & $1.79 \pm 0.13^{\mathrm{a}}$ \\
\hline II: GTS (section 1) & 1.26 & $1.87(-)$ & $1.41(+)^{* / * *}$ & 1.27 & $1.76(-)$ & $1.47(+)^{(*)}$ & $1.39 \pm 0.18^{\mathrm{b}}$ \\
\hline III: Kessiturm & 1.12 & $1.40(+)$ & $1.59(+)^{* / * *}$ & 1.23 & $1.51(+)$ & $1.55(+)$ & $1.84 \pm 0.1^{\mathrm{c}}$ \\
\hline III: Grimsel-2 & $1.15^{*}$ & $1.68(-)^{* *}$ & $1.51(-)$ & $1.17^{(*)}$ & $1.81(-)$ & $1.33(-)$ & 1.15 \\
\hline
\end{tabular}

$\begin{array}{lll}\text { III: Grimsel-2 } & 1.15^{*} \quad 1.68(-)^{* *} & 1.51(-) \\ { }^{a} \text { based on } 8 \text { measurements between about } 40 \mathrm{~m} \text { and } 77 \mathrm{~m} \text { below ground surface (bgs.) }\end{array}$

${ }^{\mathrm{b}}$ based on 9 measurements between about $490 \mathrm{~m}$ and $530 \mathrm{~m}$ bgs. (section 1 is closest to the model observation point).

${ }^{\mathrm{c}}$ based on 7 measurements between about $320 \mathrm{~m}$ and $570 \mathrm{~m}$ bgs. 


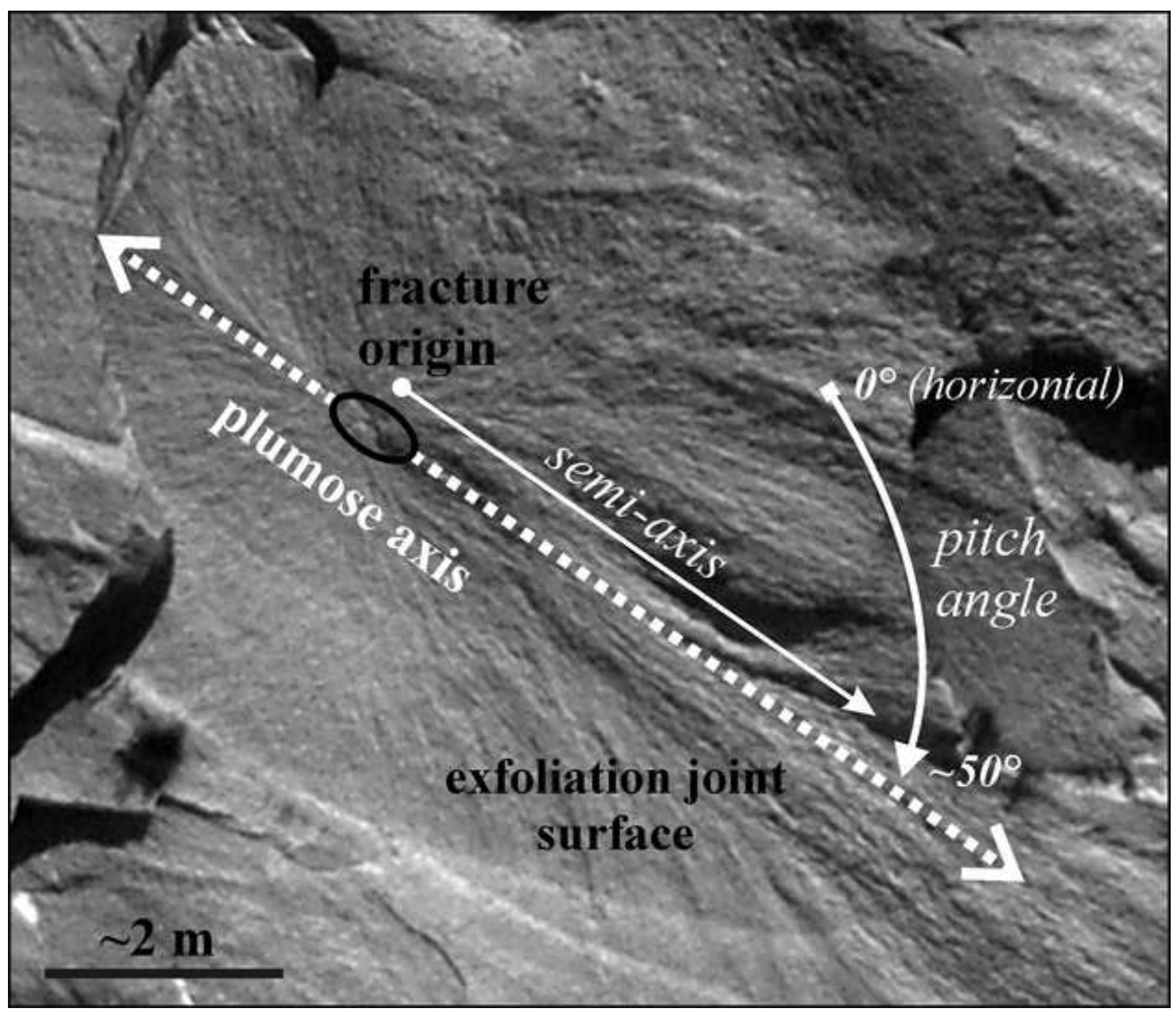




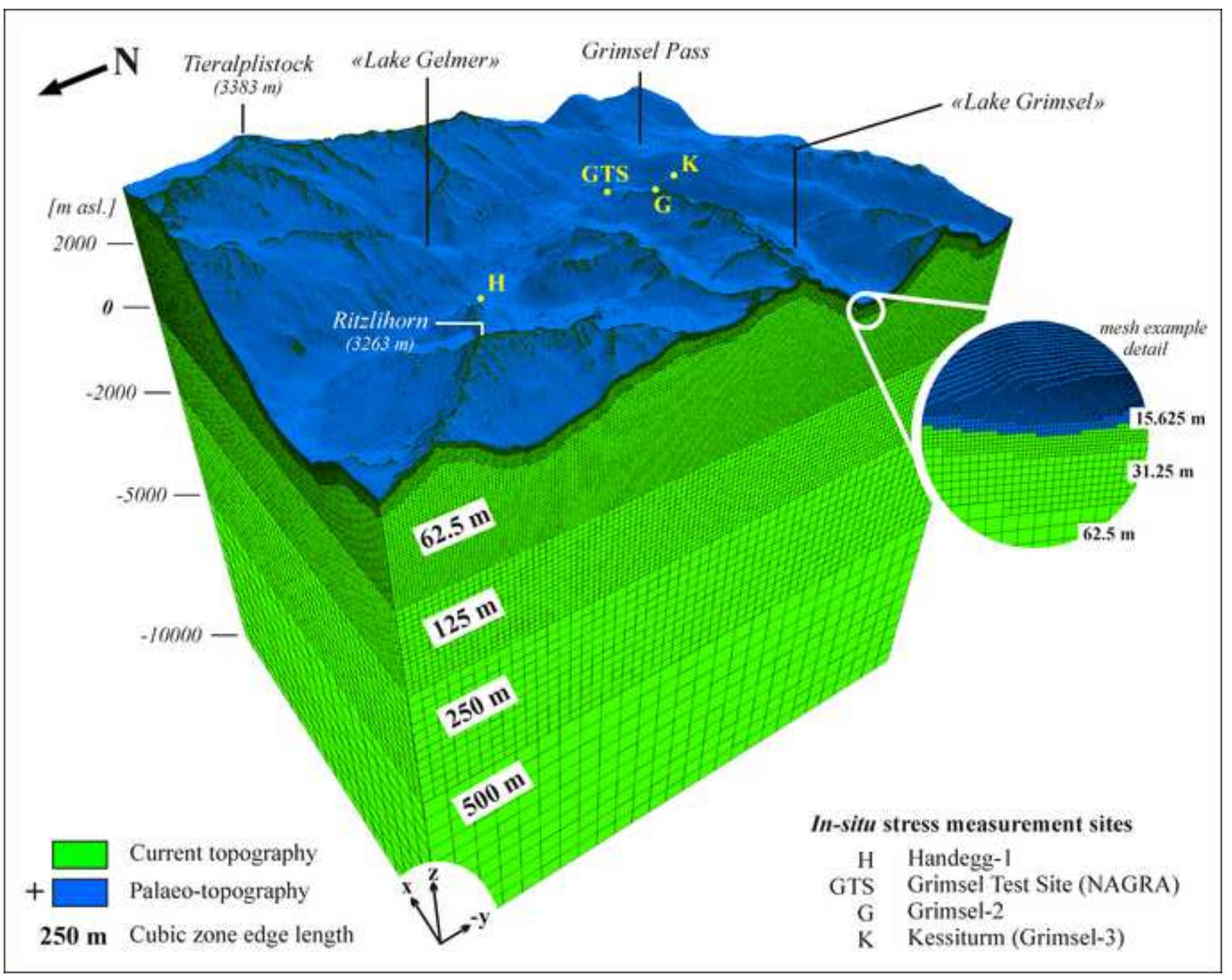




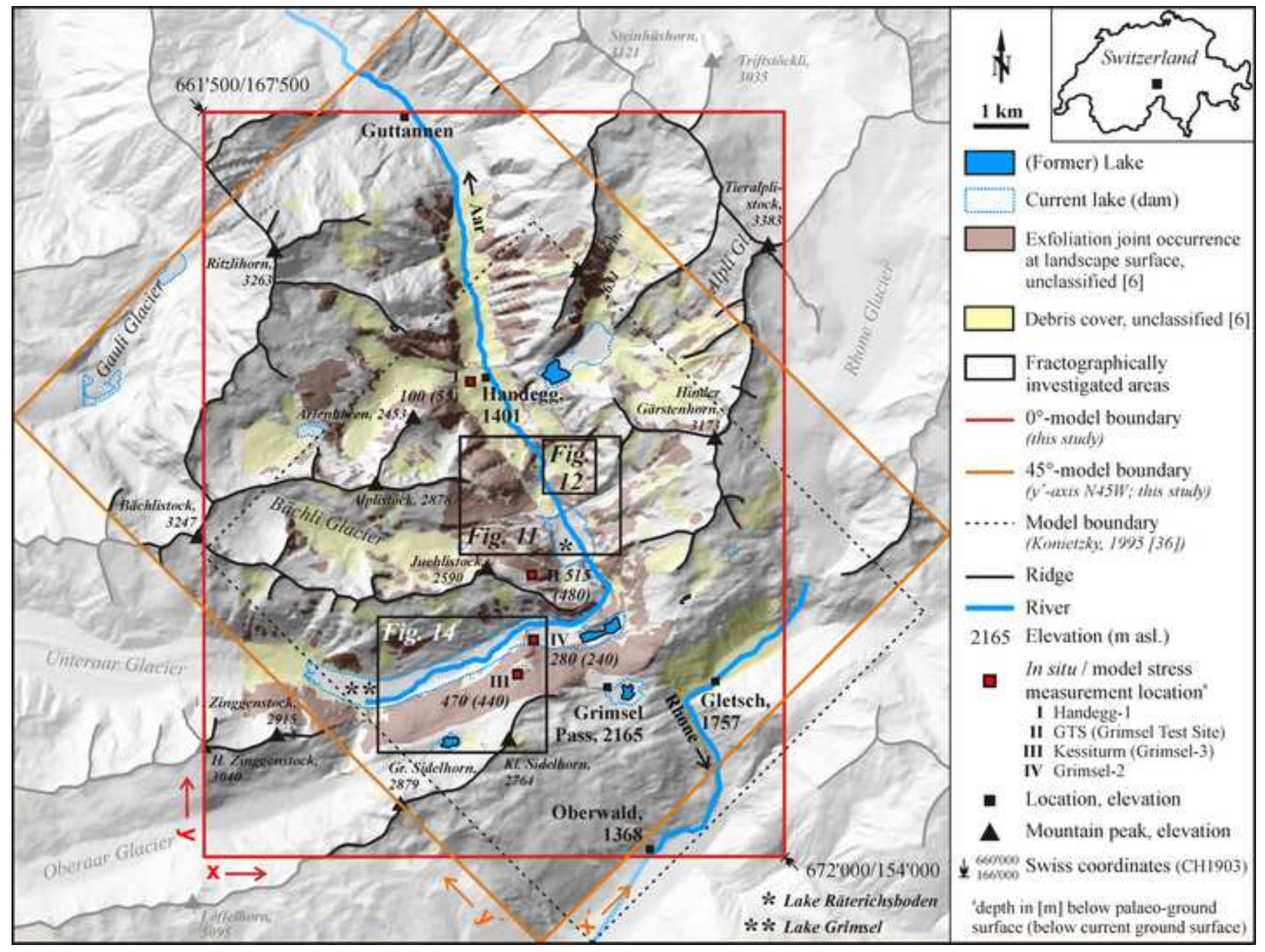




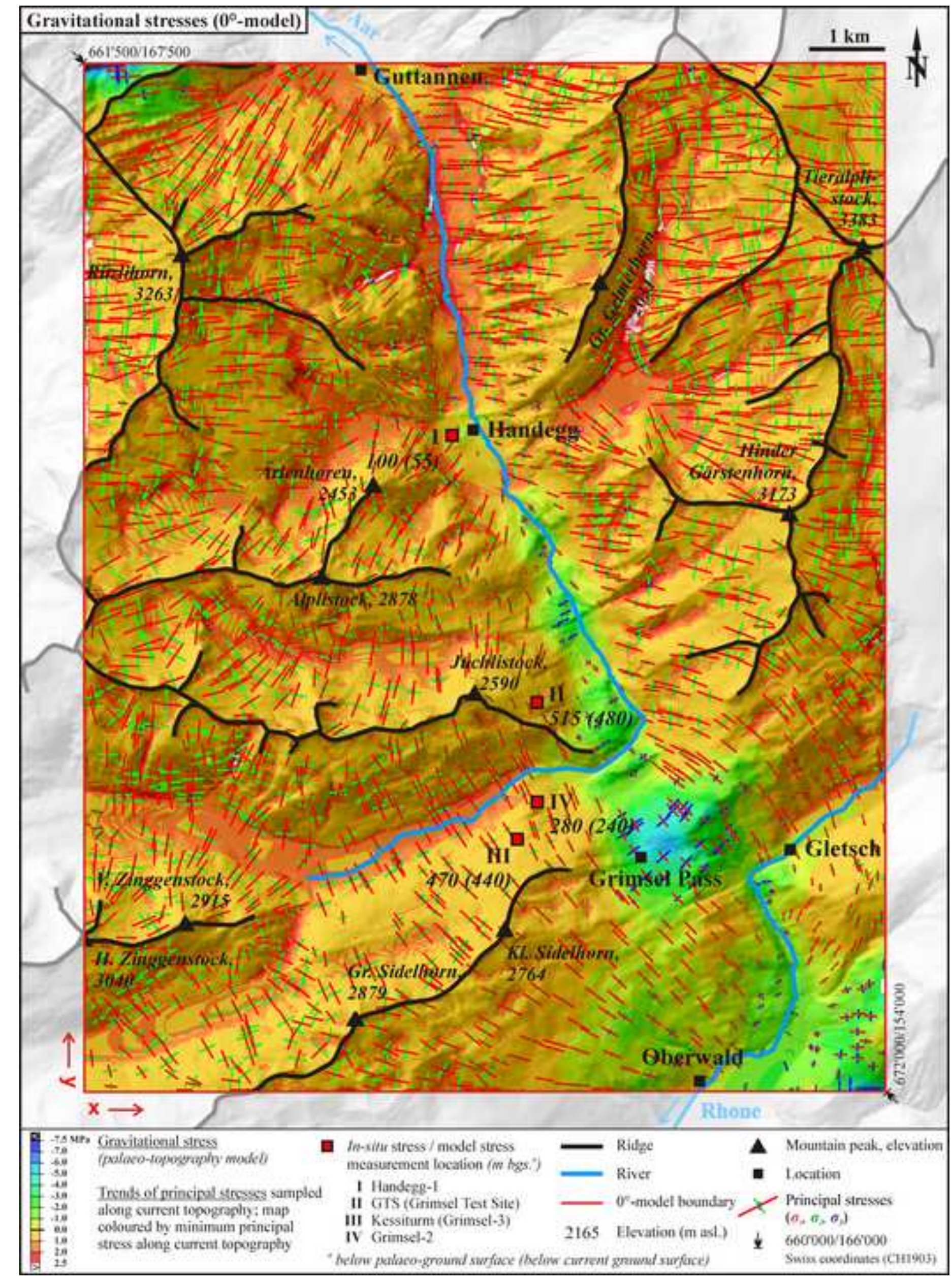

Figure 04 revised 


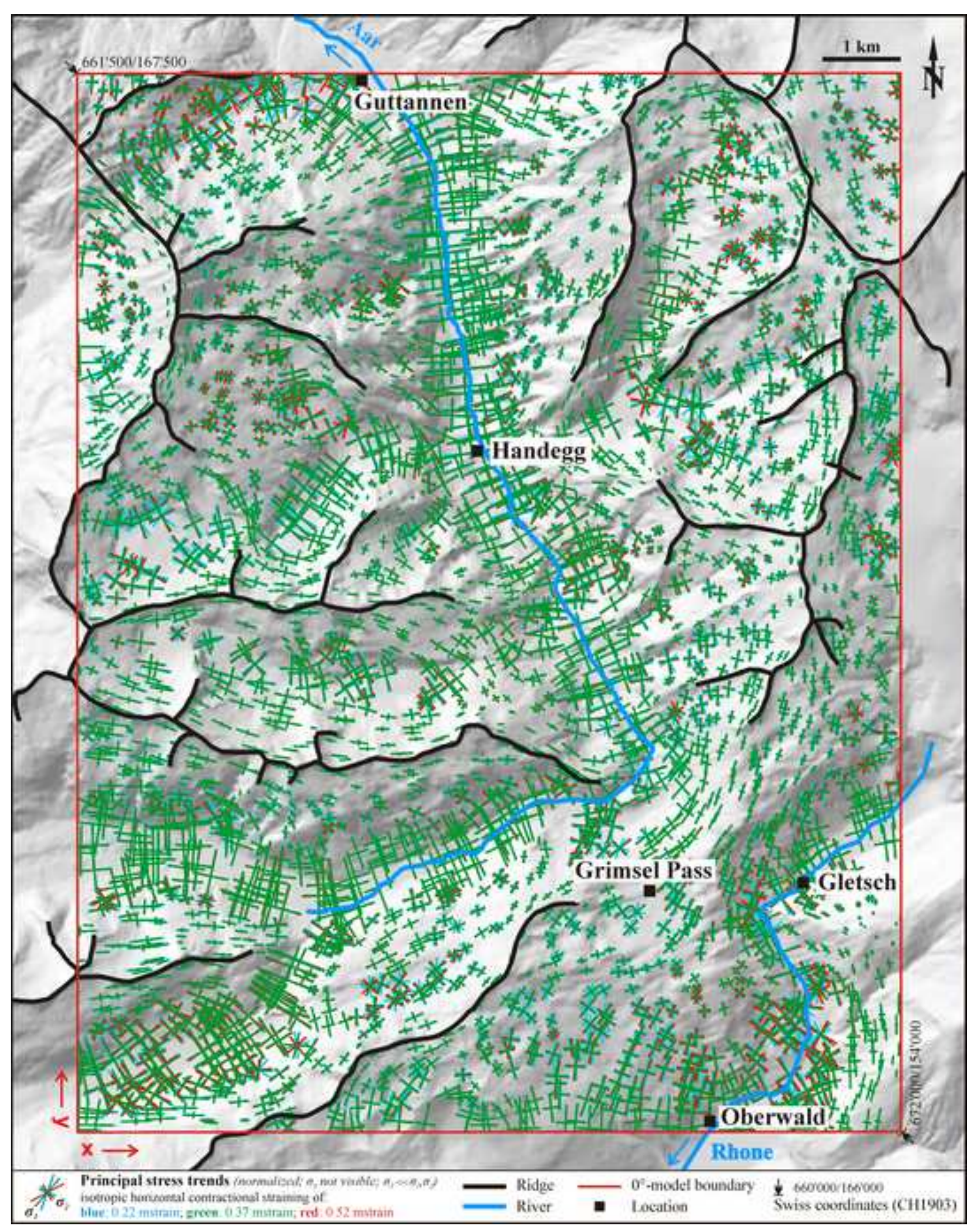




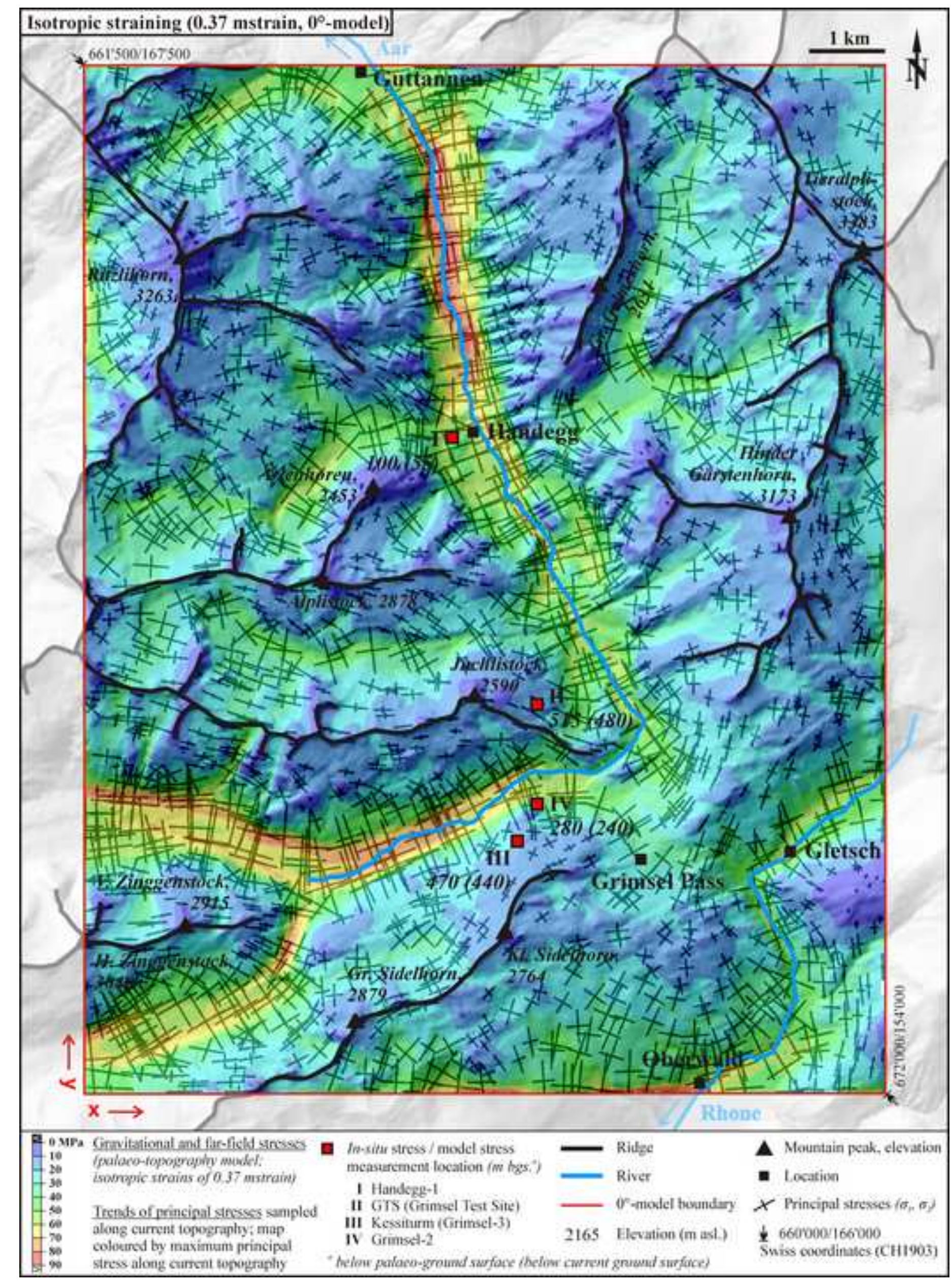

Figure 06 revised 


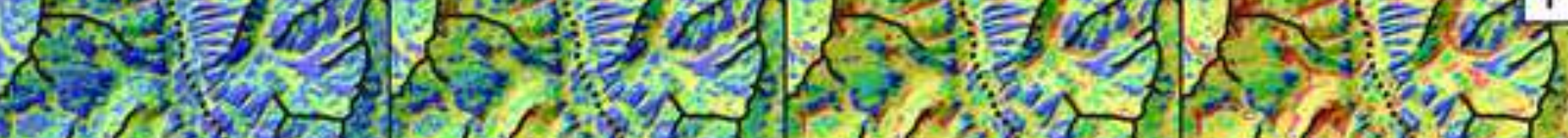

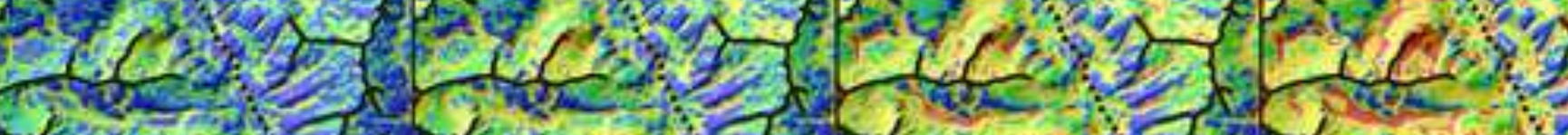

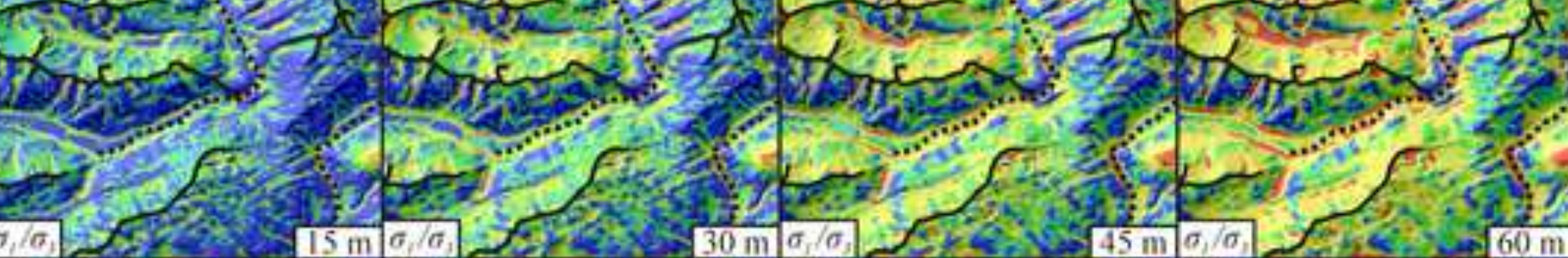

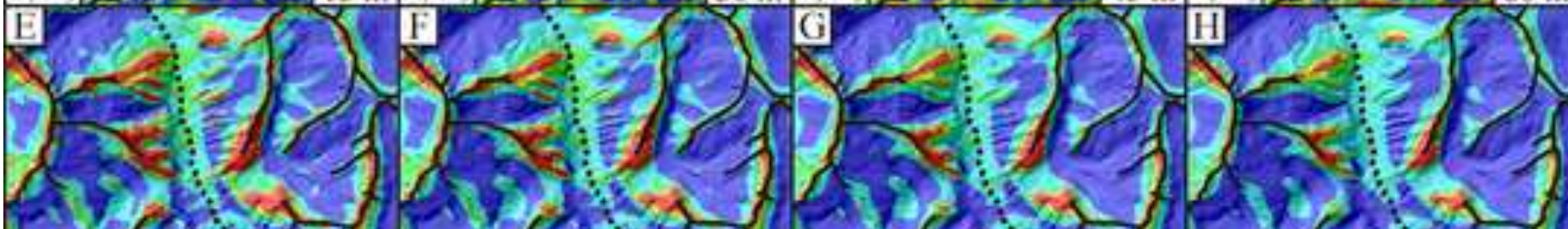

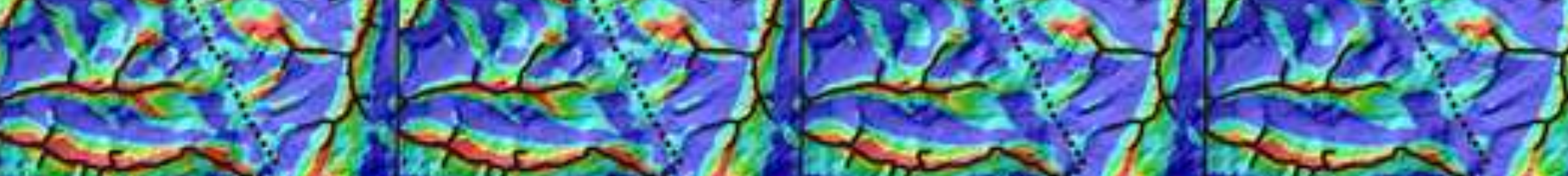

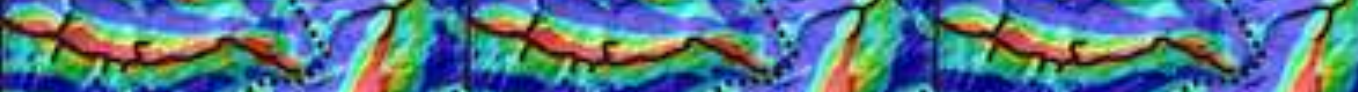

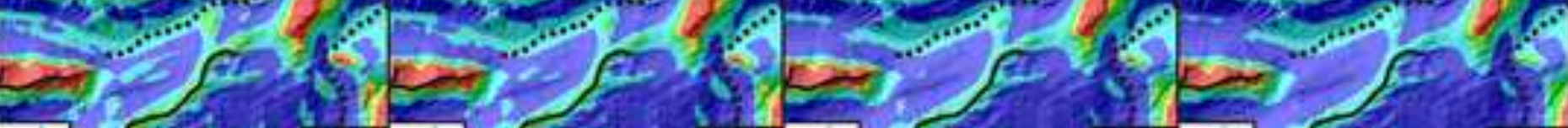

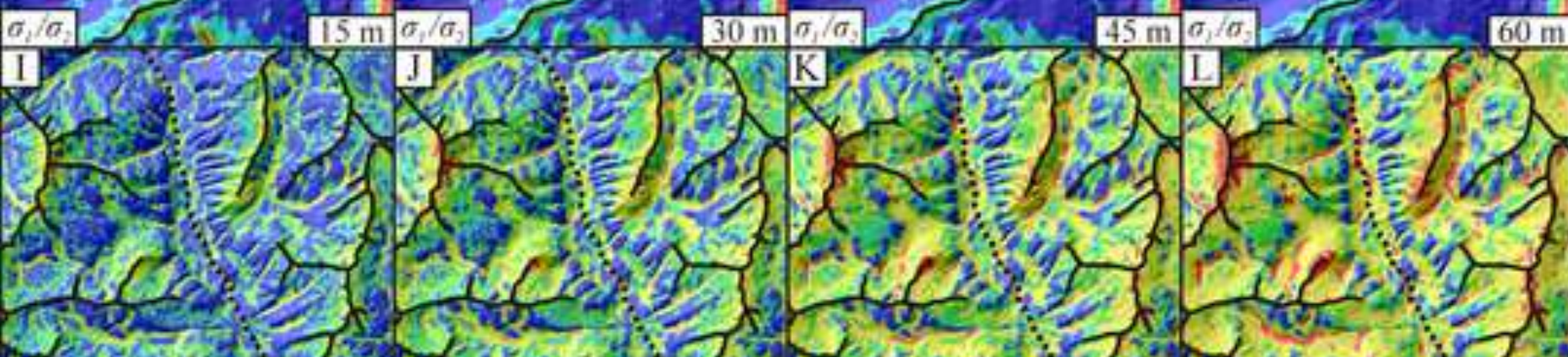

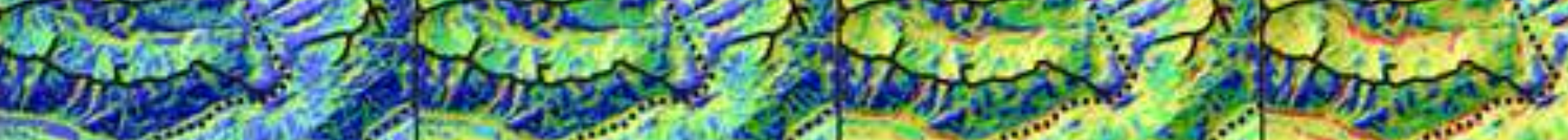

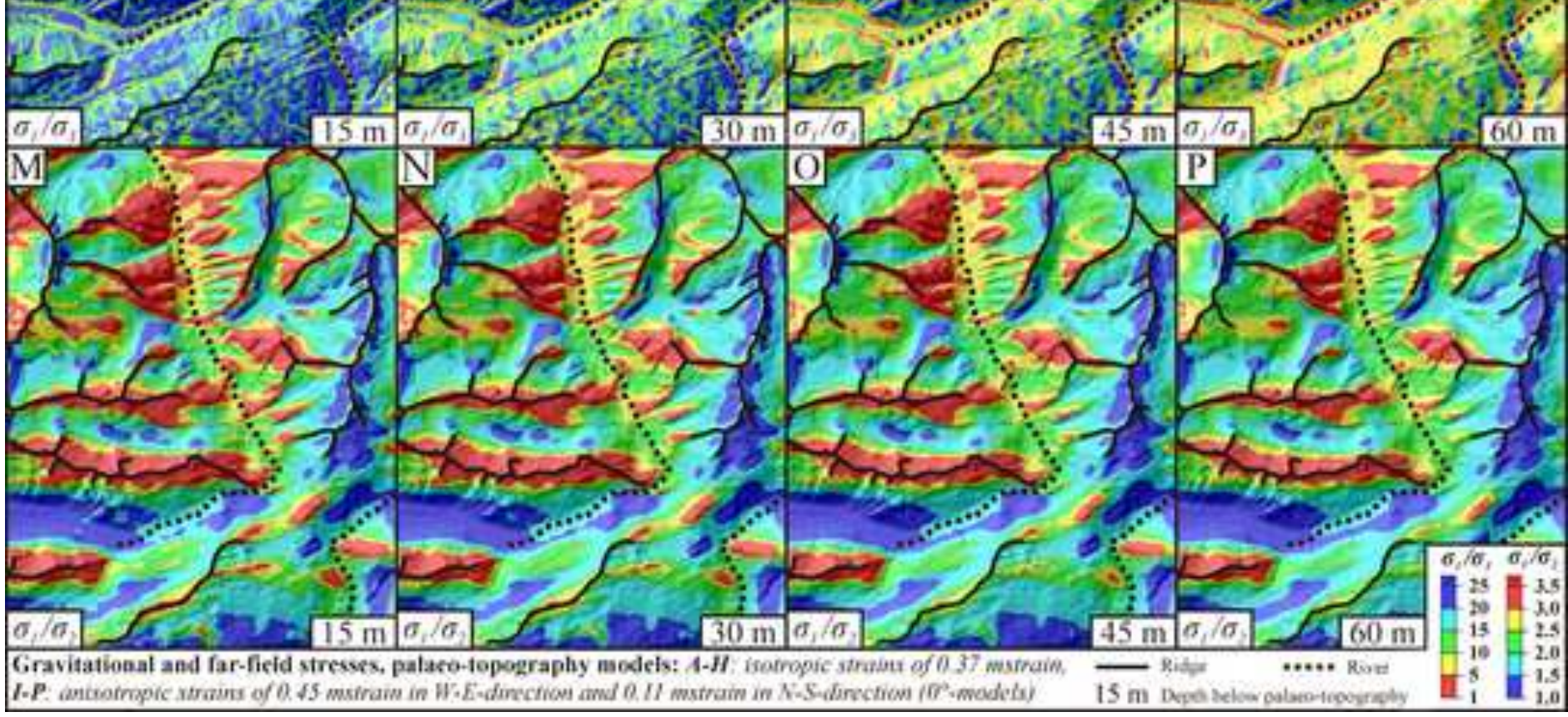




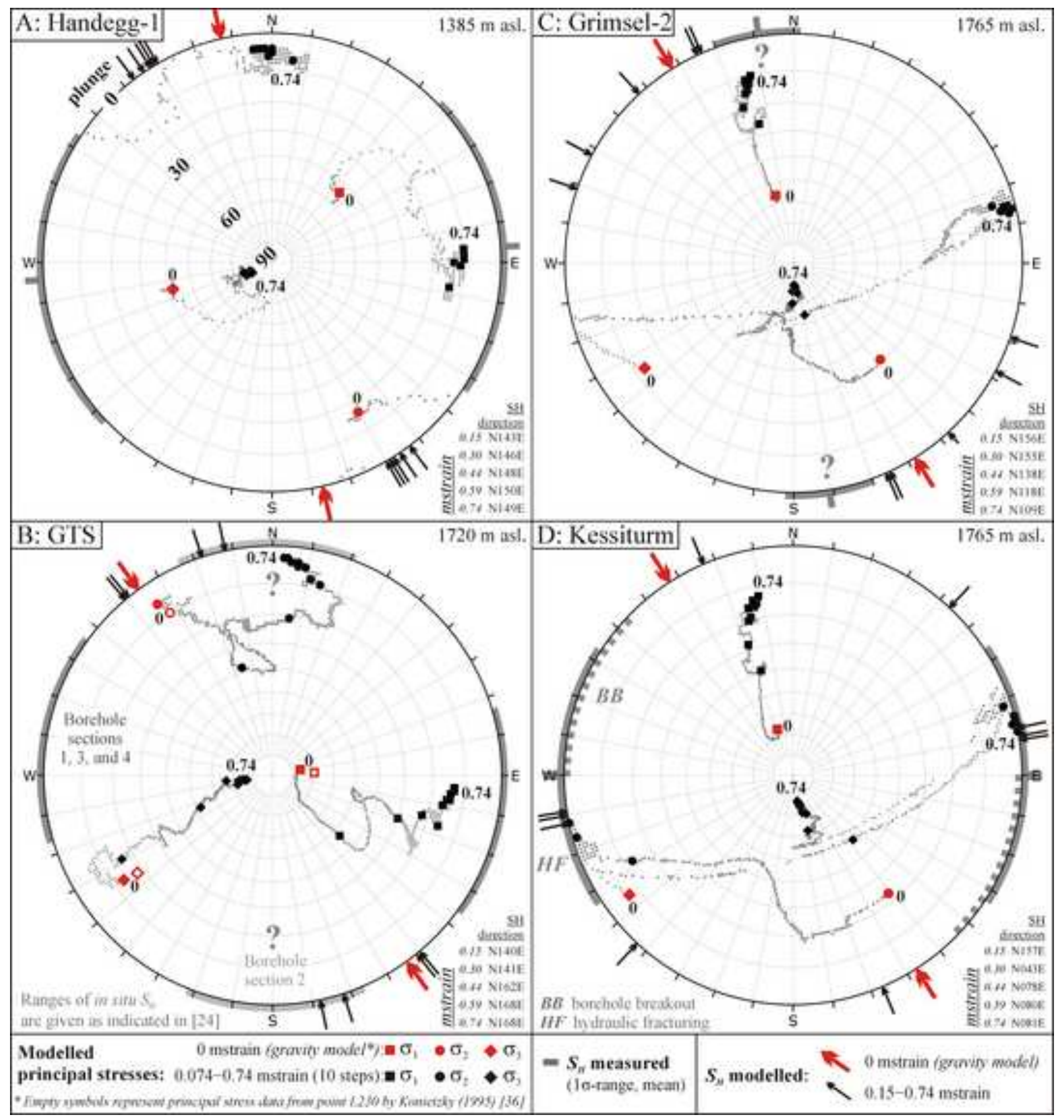




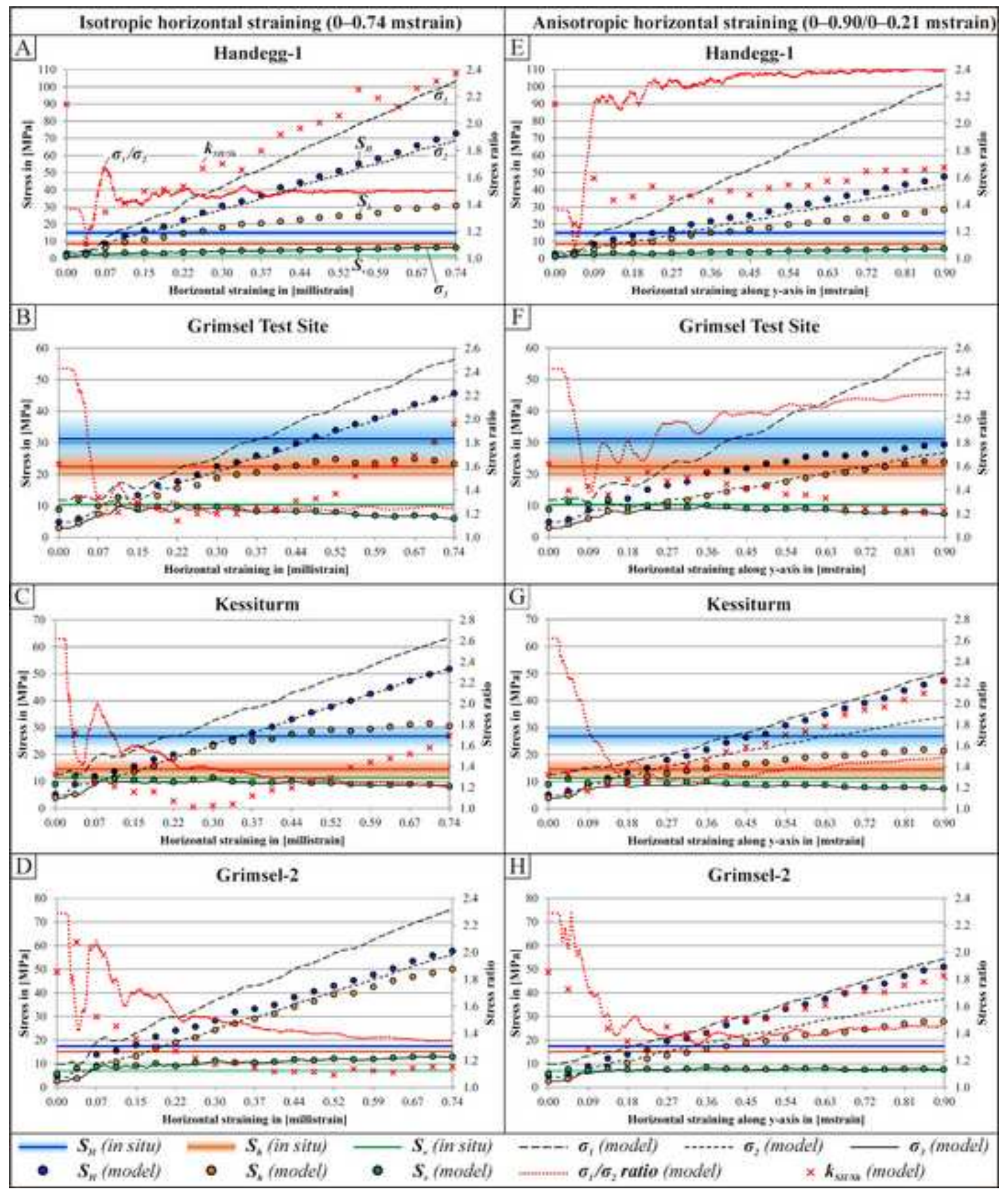




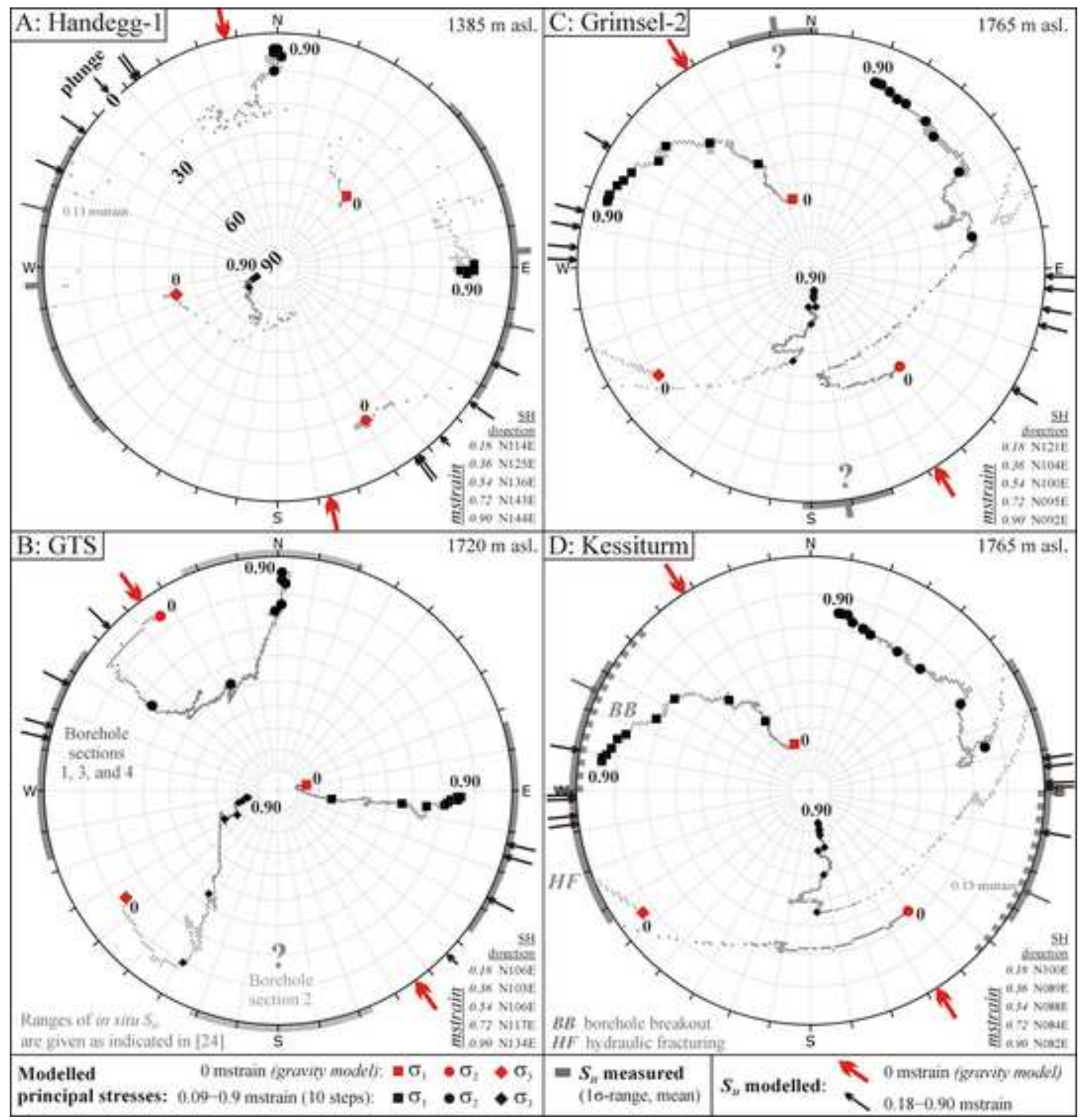




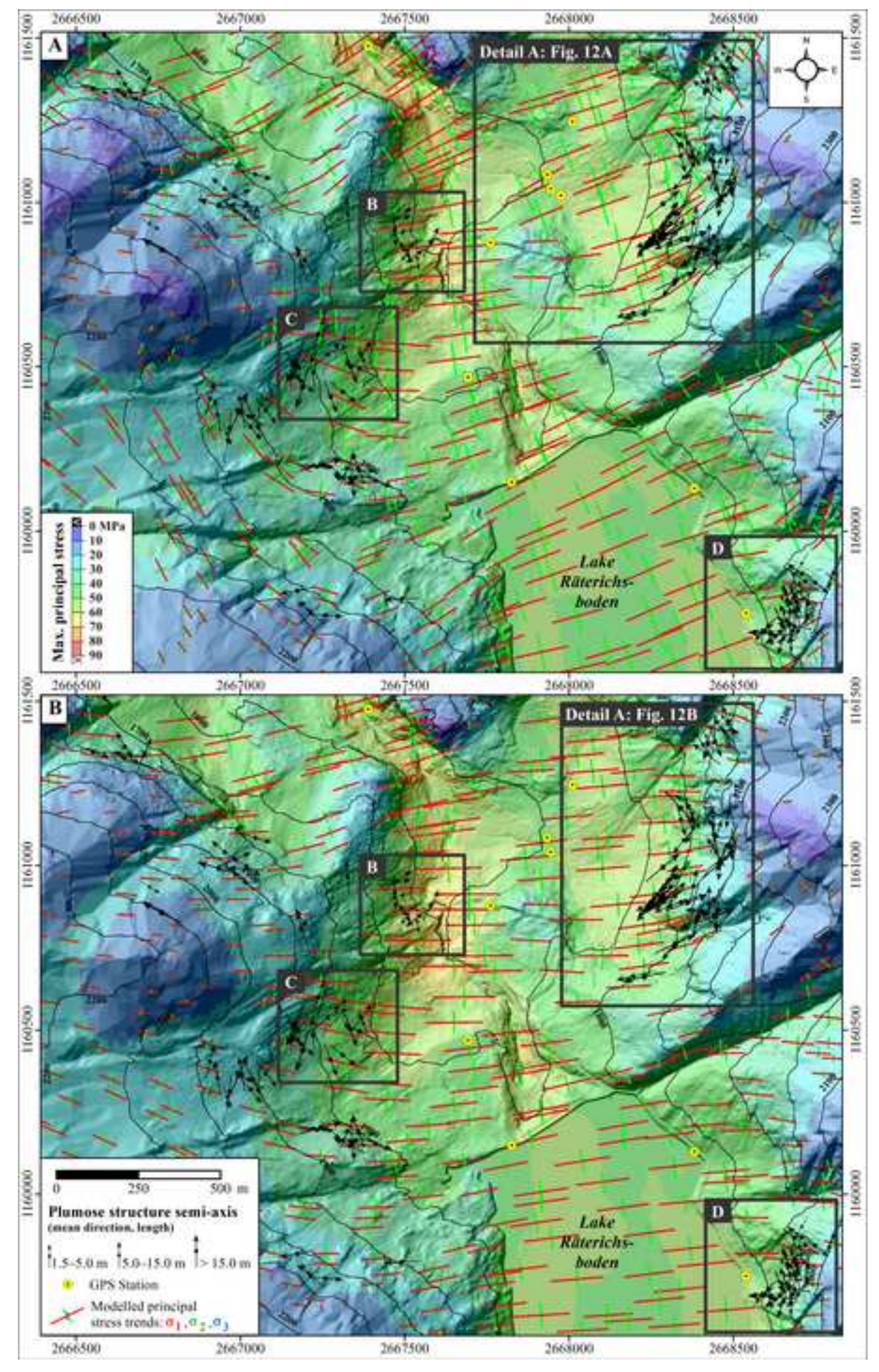

Figure 11 revised

.




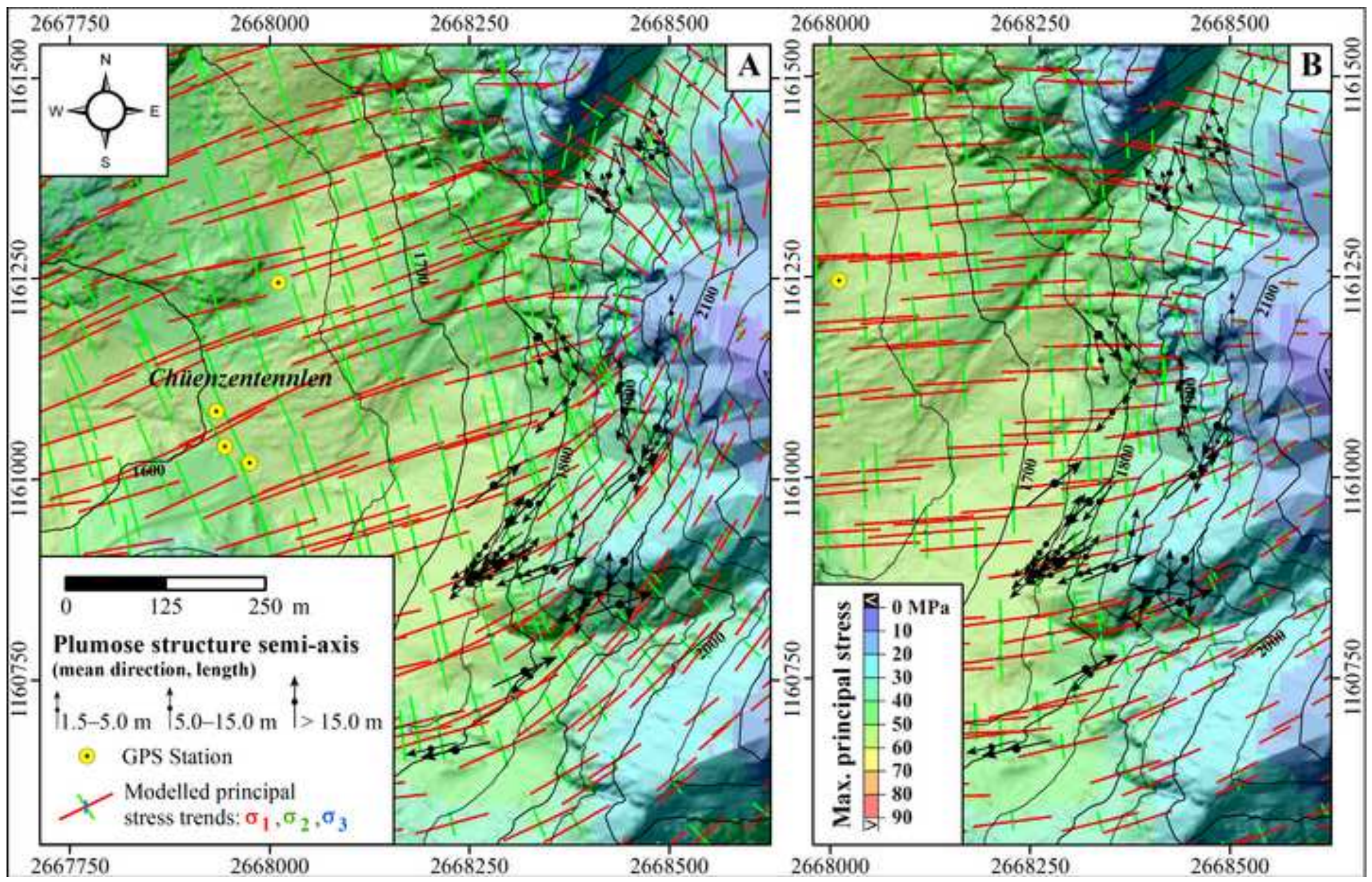




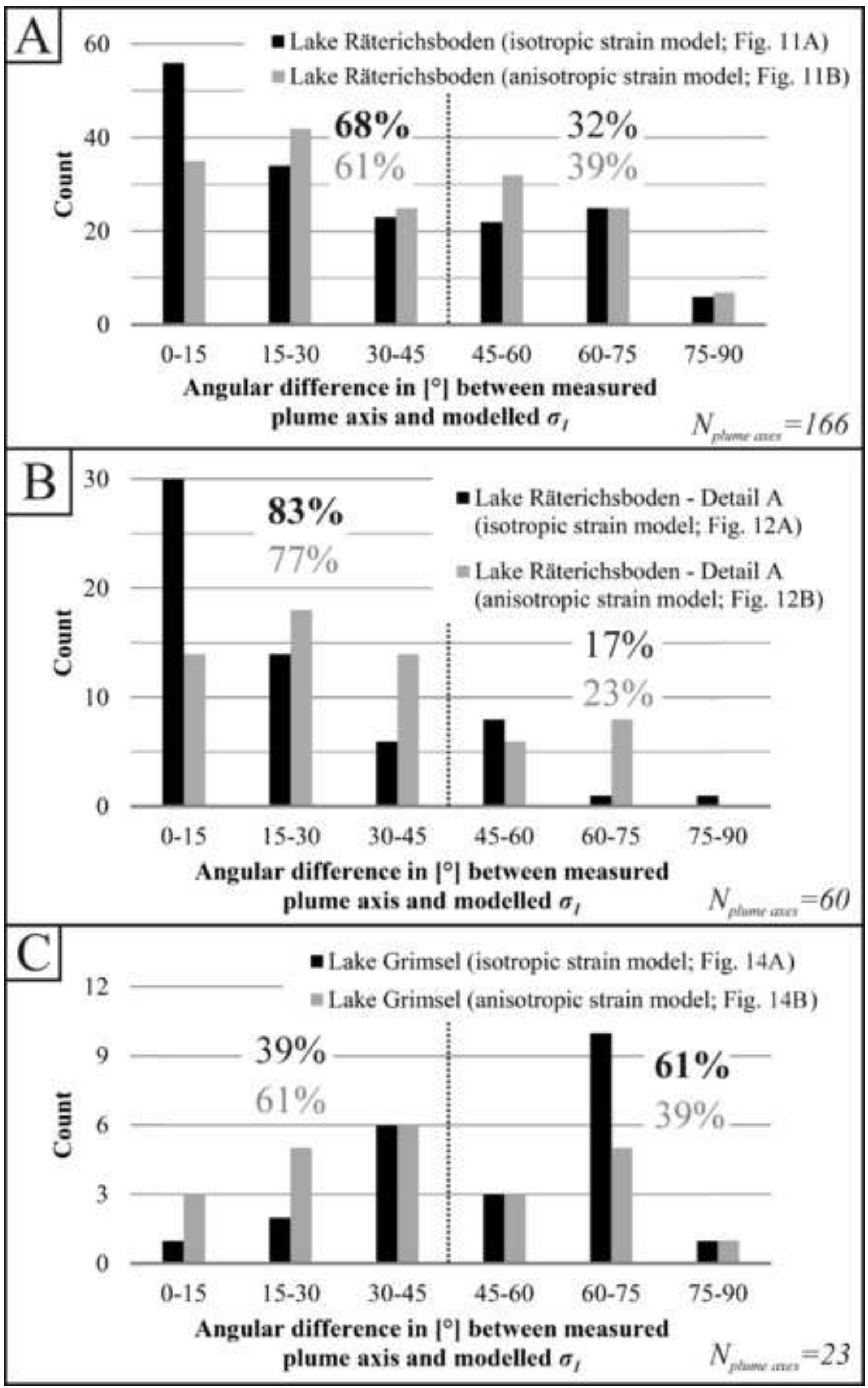




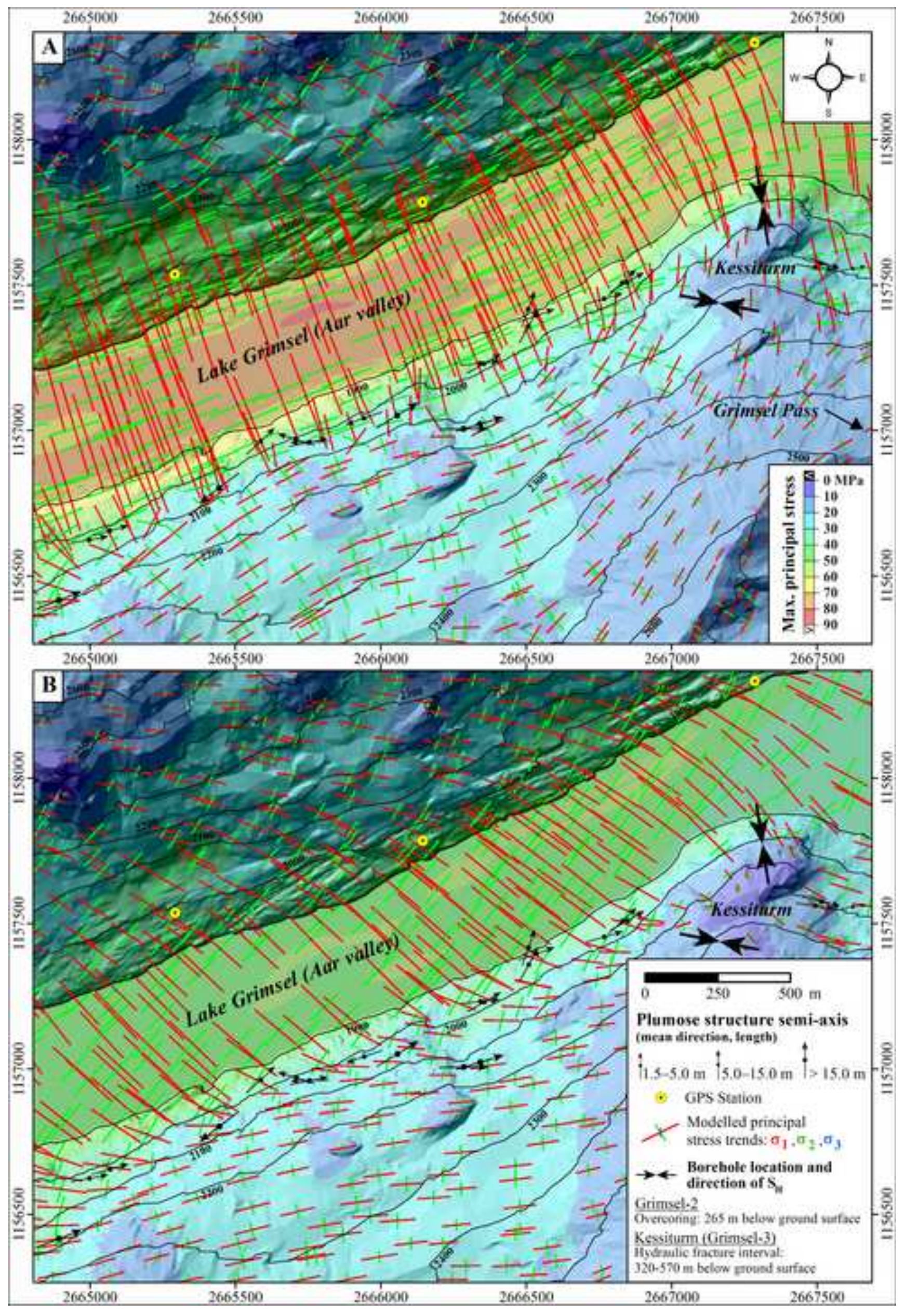

Figure 14 revised 


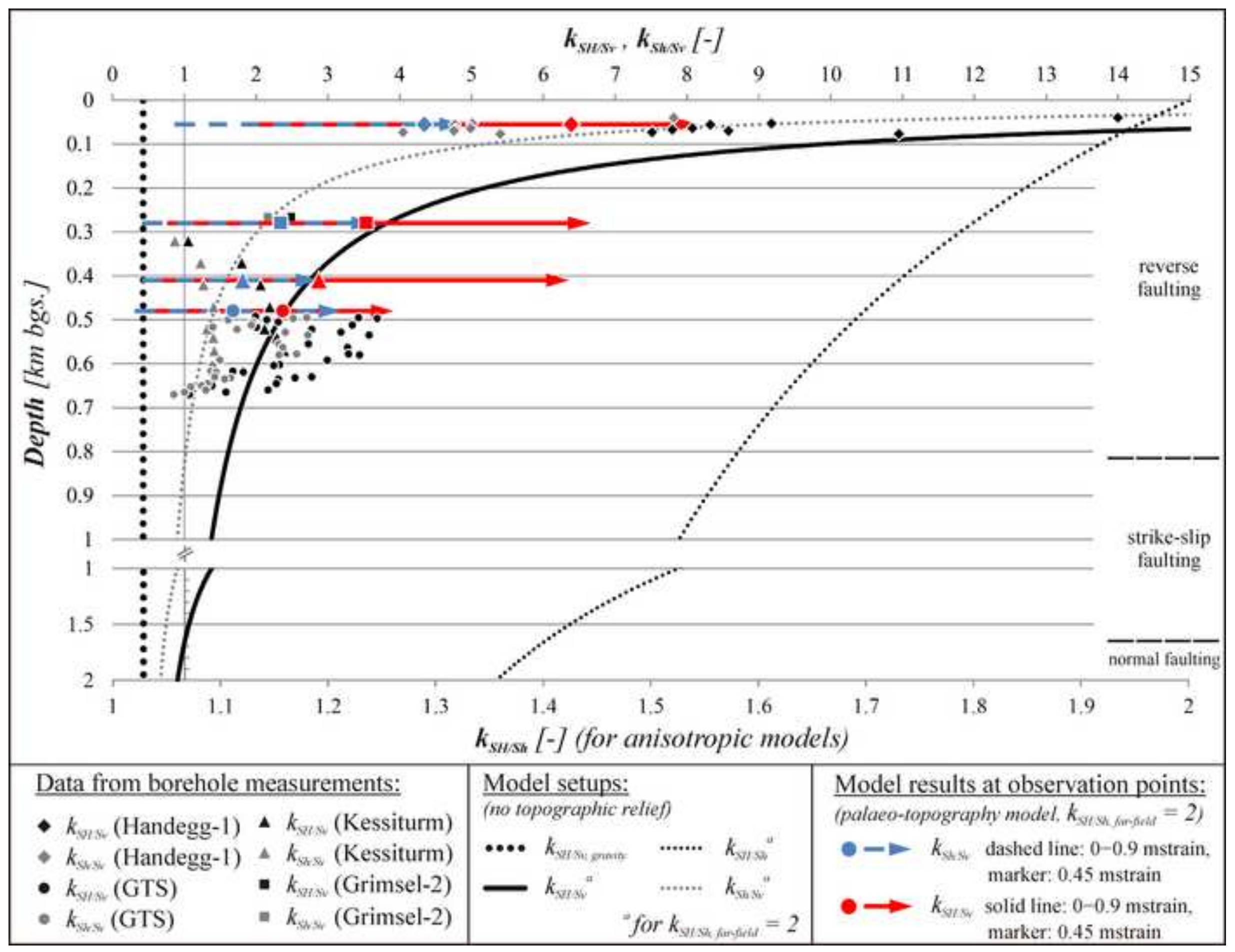




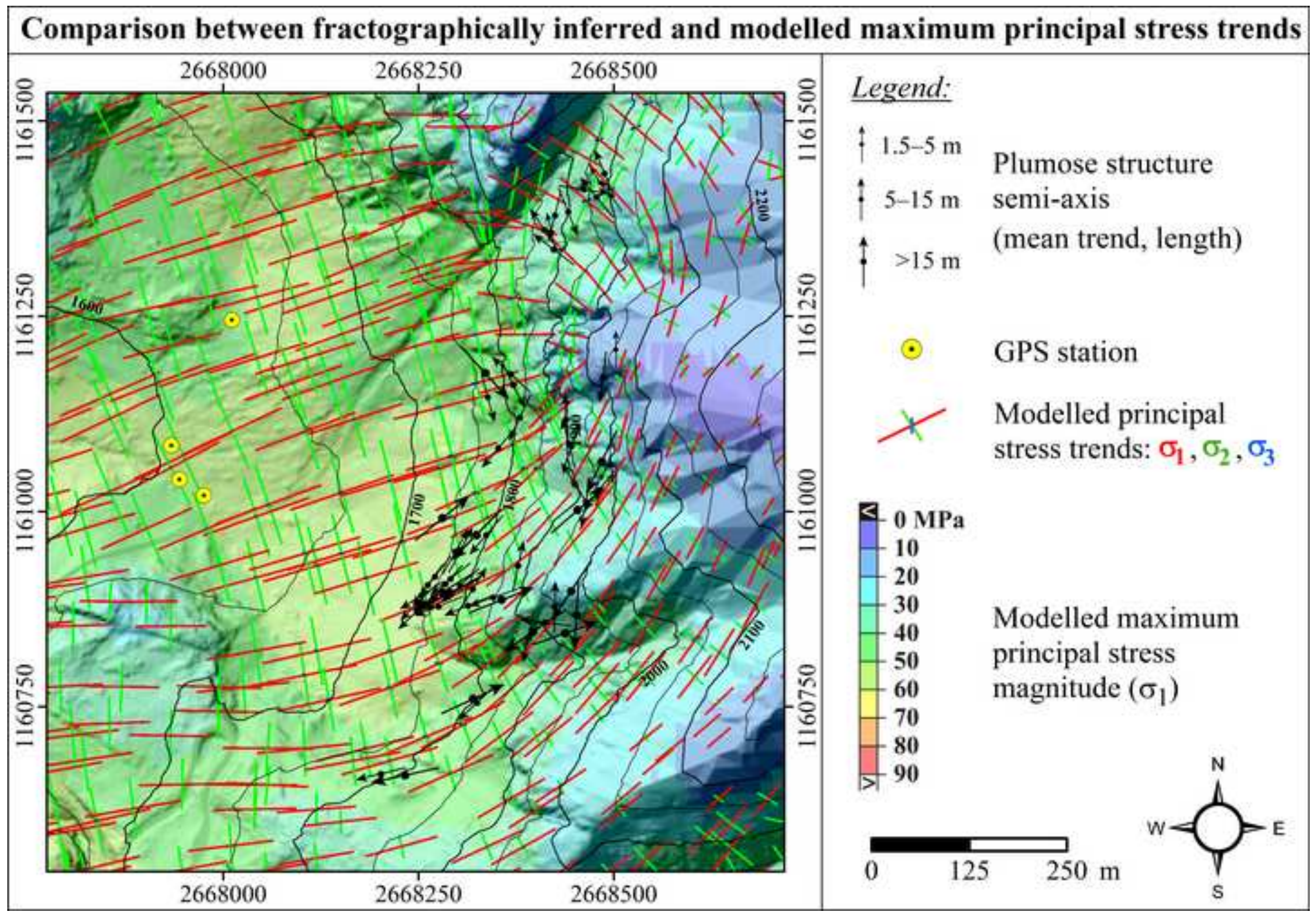

